\title{
قلق المستقبل وعلاقته ببعض المتغيرات لدى طلبة التكوين المهني
}

\author{
زقاوة أحمد \\ المركز الجامعي- غليزان، الجزائر
}

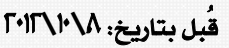

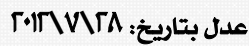

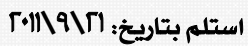

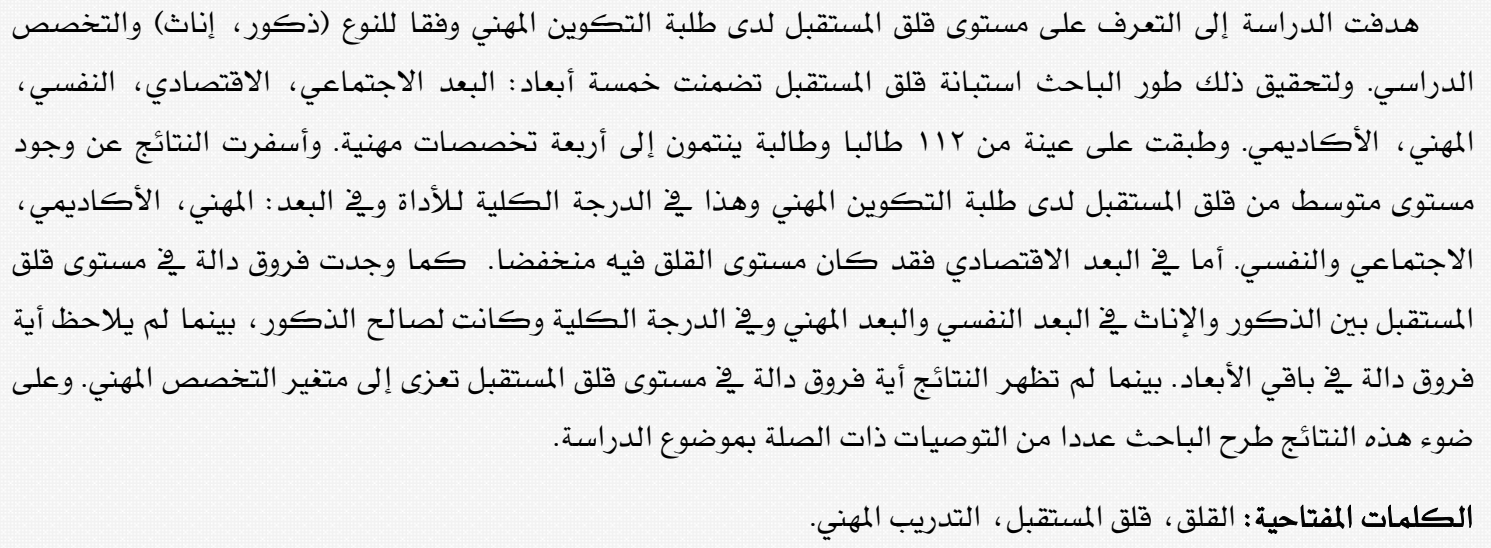

\section{The Relationships of Future A nxiety with some Variables among the V ocational Training Students}

\author{
Zegaoua A hmed* \\ University Center of Relizane, Algeria
}

The Purpose of this study was to investigate the level of future anxiety among students of' vocational training. The relationship of future anxiety gender and vocational specialization was tested. The researcher developed a questionnaire of future anxiety which was distributed to 112 students who were in four vocational specializations. The results revealed that there was an average level of future anxiety among the vocational training students, in the total score as well as in the vocational, academic, social, and psychological dimensions. However, there was low level of future anxiety in the economic dimension. There were also statistically significant differences between males and females on the level of future anxiety, while there were no statistically significant differences on the other dimensions attributed to the vocational specialization. In light of the findings the researcher proposed a number of recommendations.

Keywords: anxiety, vuture anxiety, vocational training.

*a zegaoua@yahoo.fr 
عواهل أخـرى كتقـدير الذات والفعـالية الشخـصية

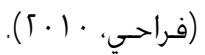

\section{الإطار النظري للدراسة:}

\section{مفهوم القلق}

يشـير مصـطلح القلق إلى انفعال غير سـار وشـعور

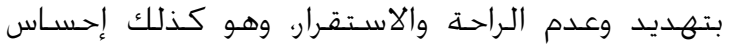

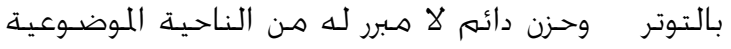

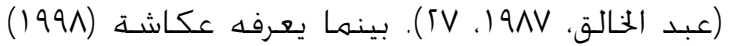

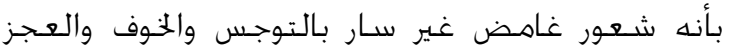

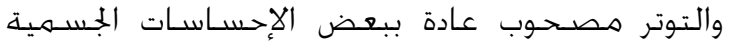

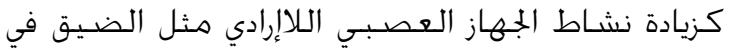

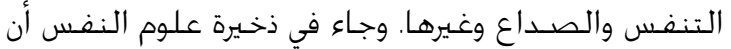
القلق له أربعة معان:

1 - إحسـاس بمزيتج مـن الرهبة والإشـفاق مـن المسـتقبل

$$
\begin{aligned}
& \text { بدون داع معين للخوف. } \\
& \text { أ - خوف مـزهـن بـدرجـة خـفيفـة. }
\end{aligned}
$$

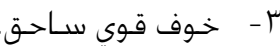

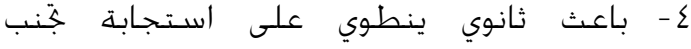

$$
\text { مكتسبـة. }
$$

ورغم اختـلاف الباحثين حول حتديد هؤشـرات القـلق

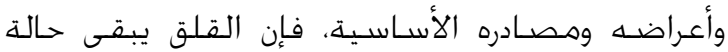
انفعالية يتعرض لها الفـرد في مختلف المواقف الحياتية

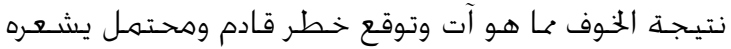
بالعجز وعدم القـدرة على المواجهة.

النظريات المفسـرة للقلق: تعددت النظريات المفسـرة

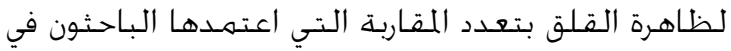

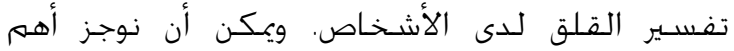

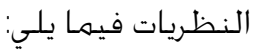

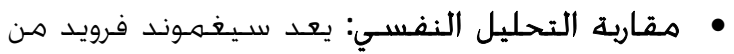

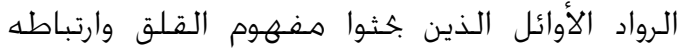

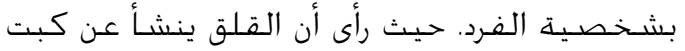

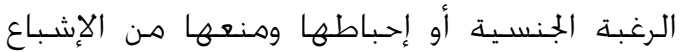

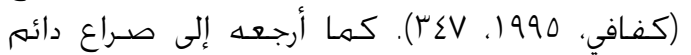

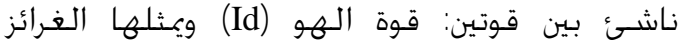
واللكبوتات وقوة الأنا الأعلى وهي قوة لـوة الضـمـير وكل أشـكال السـلطـات الخارجيـة. وقد تطورت دراسـات القلق في إطلار مقاربة التحليل

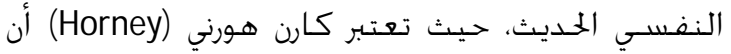

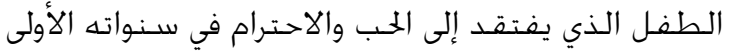

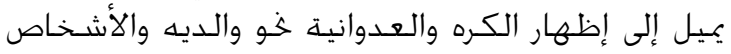

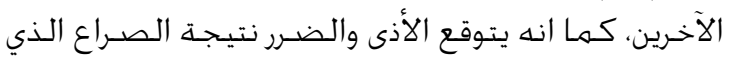

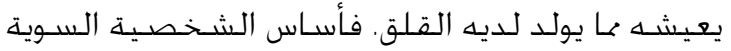

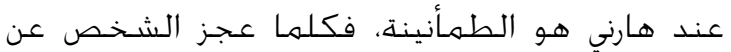

يعيش الفـرد اليوم أكثر مـن أي وقت مضـى في حالة

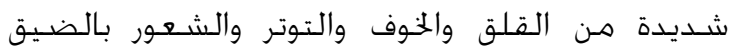

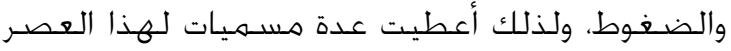

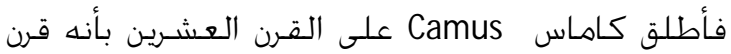

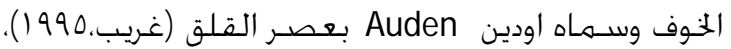

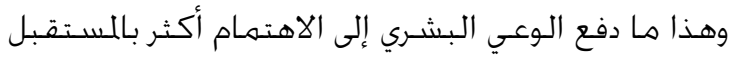

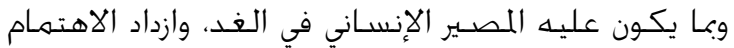

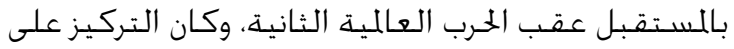

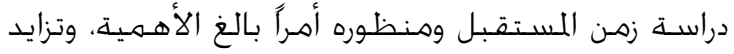

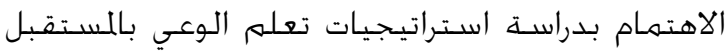
وأدوات قياســ (Passig, 2001).

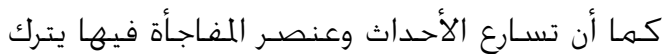

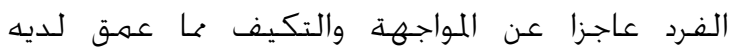

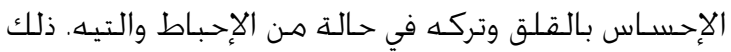

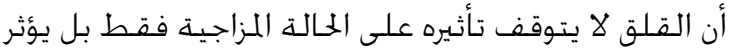

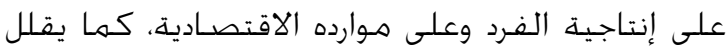

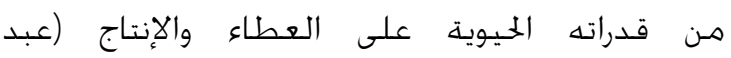

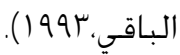

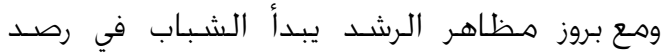

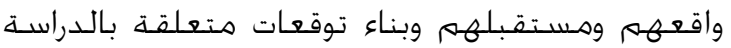

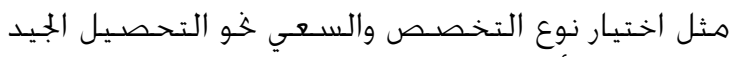

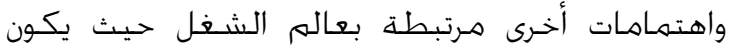

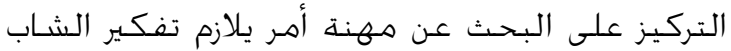

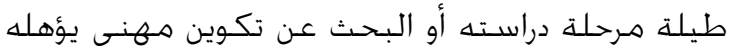

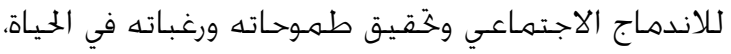

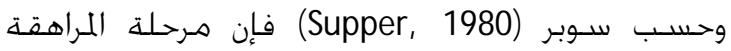

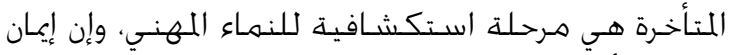

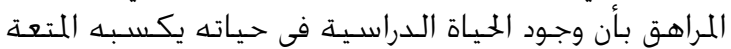

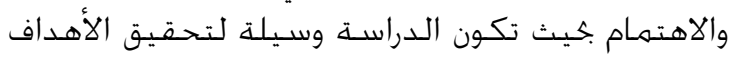

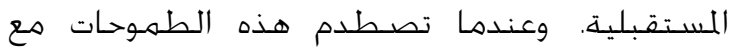

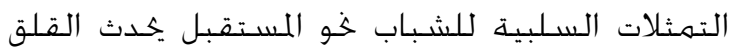
وترتفع حسته أكثر.

وإذا كان قلق المسـتقبل ينتشـر لـى فئات عديدة هـن

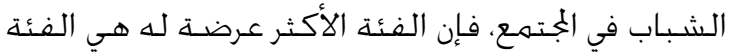

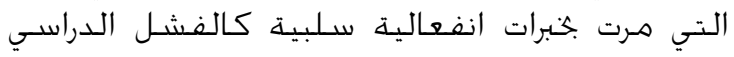

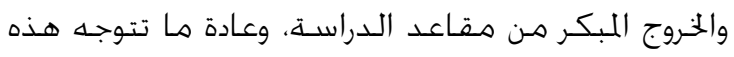

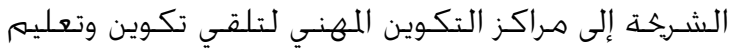

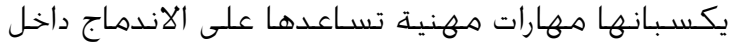

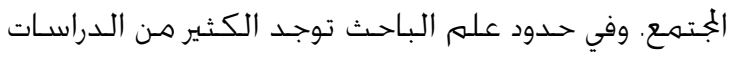

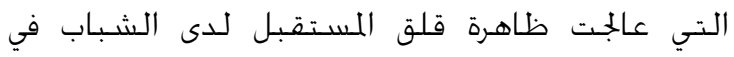

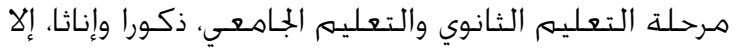

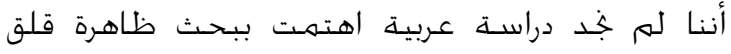

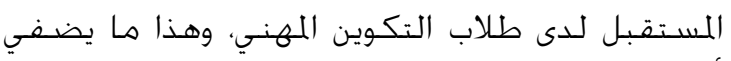

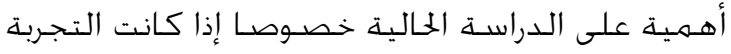

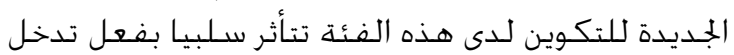


تلك المخاطر (تونسي، ؟ . ؟). ومعرفيا، فالفرد يقلق

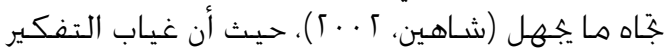

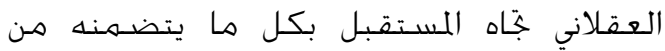

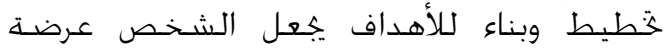
للقلق والاضطراب. كما أن الأهداف غير الواقعية التهافية

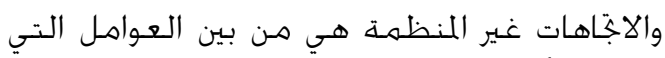

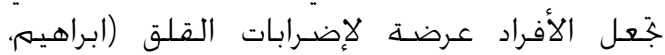
( $(\ulcorner+1$

تعريف قلق المستقبل: يعد قلق المستقبل مـن أكثر إلـر

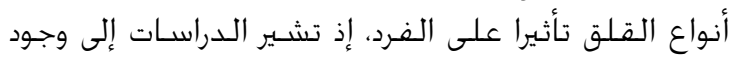

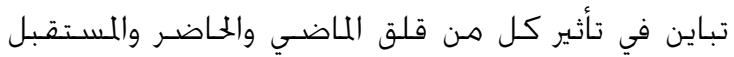

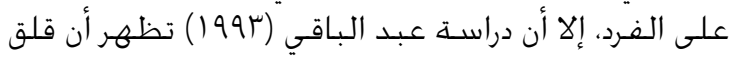

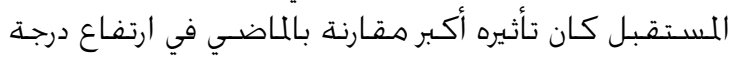

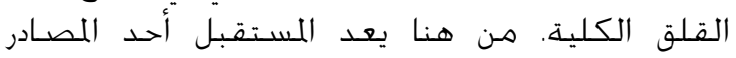

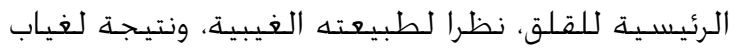

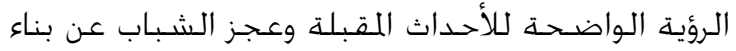

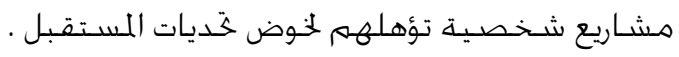

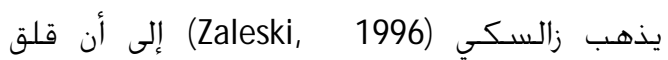

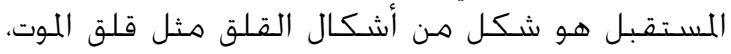

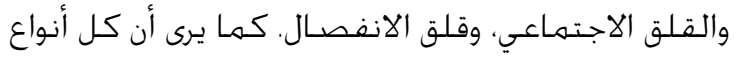

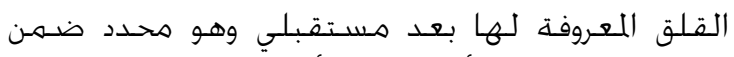

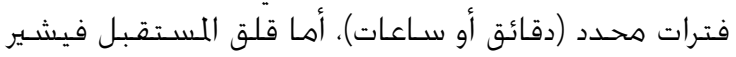

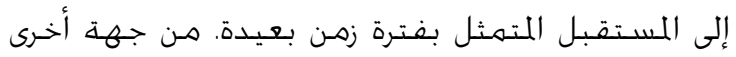

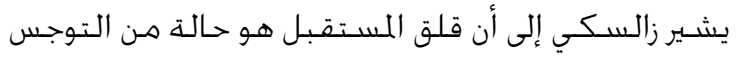

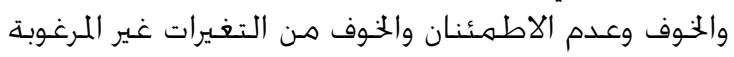

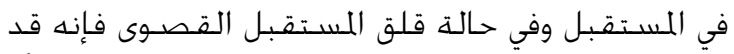

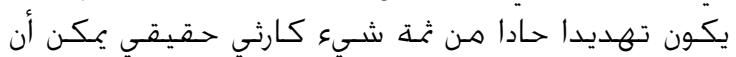

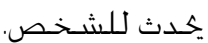

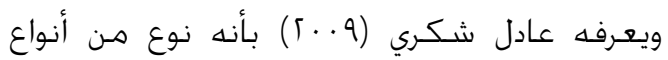

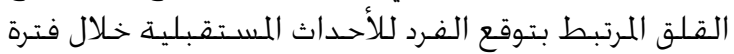

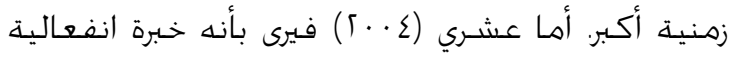

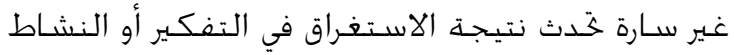

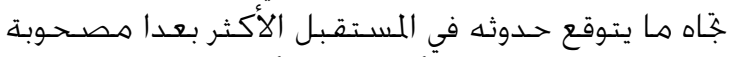

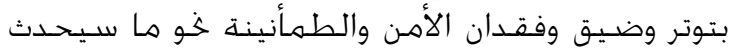

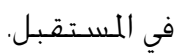

يظهر من التعريفات السابقة أن قلق المستقبل

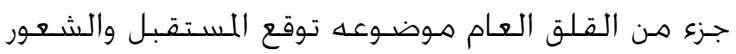

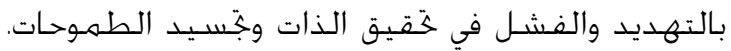

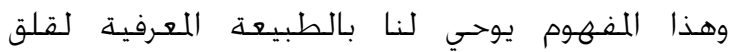

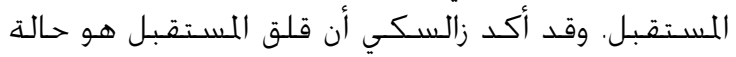

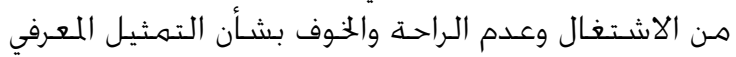

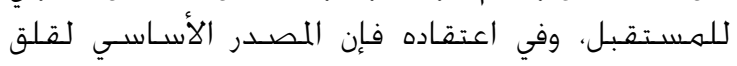

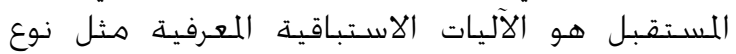

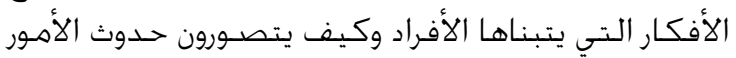

.(Zaleski, 1996)
الوصـول إلى الطمأنينة كلما كان أكثر قلقا وتوترا

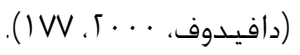

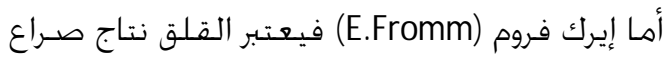

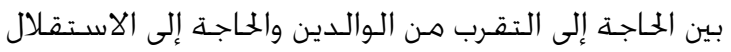

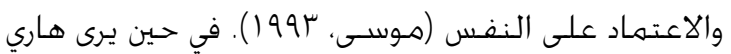

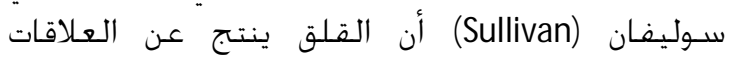

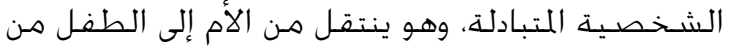

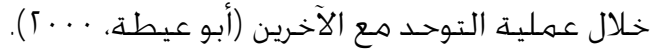

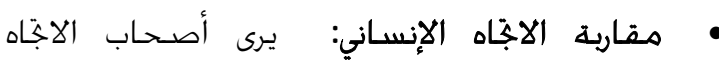
الإنساني أن القلق ينتج عن الإنساني: تهديد للحاجات

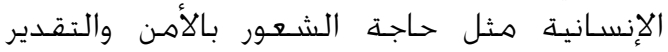

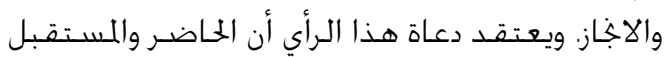

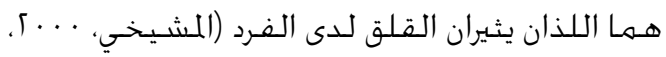

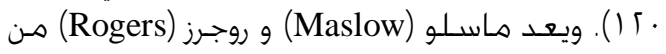

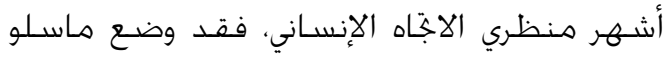

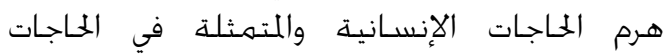

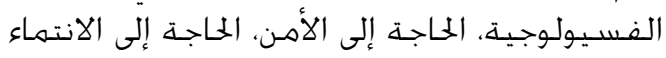

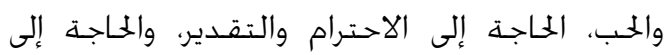

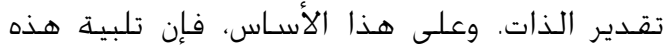

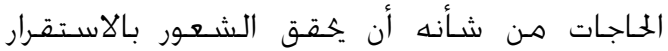

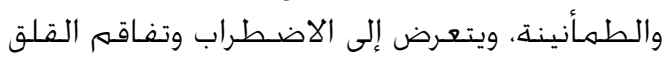

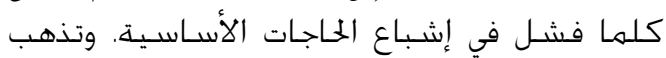

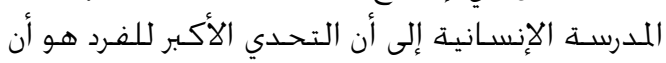

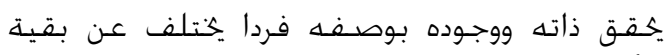

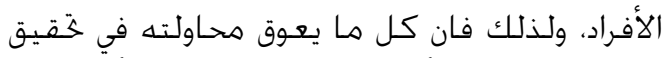

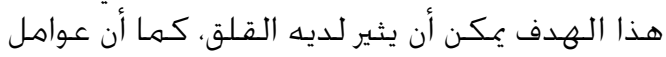

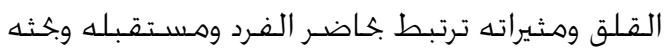

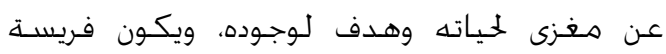

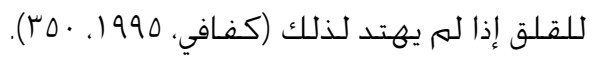
• مقاربة الاجّاه السلوكي: يحاول السـلوكيون جناوز

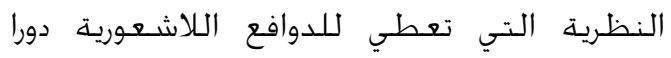

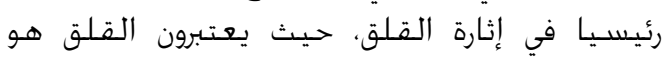

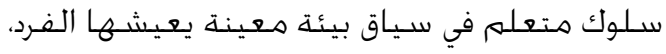

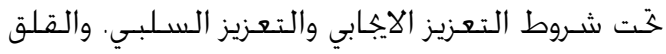

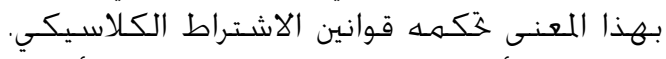

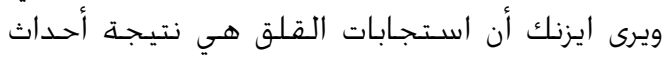

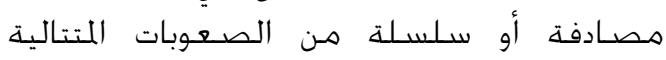
تشتهـل على رد فعل عصل عصبي لا إرادي (الماميد والسفاسفة، V. • ( ).

المقارية المعرفية: يعتبر بيك (Beck) من المساهمين المين

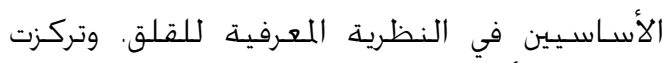

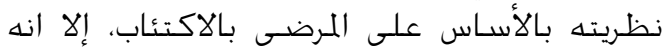

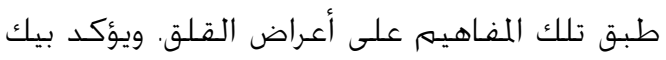

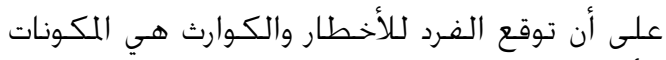

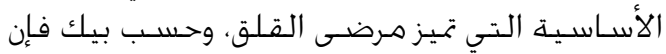
القلق يتوقف على الطريقة التي يدرك بهر التها الفرد 
الدراسـة إلى وجود اختلاف في مصادر الضغوط النفسية

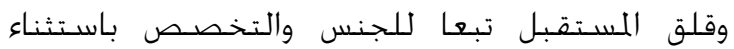

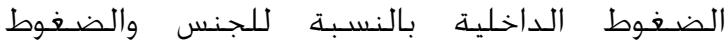
الأكاديمية بالنسبة للتخصص.

كما أجرى زالسكي (Zaleski, 1996) دراسـة حول النجاء الاستجابات النفسية والفسيولوجية أثناء ختيل الفيل الفرد الفيد

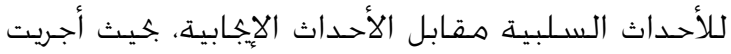

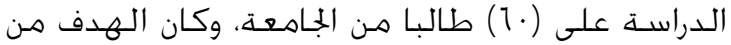

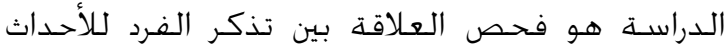

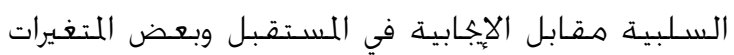

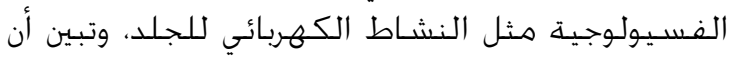

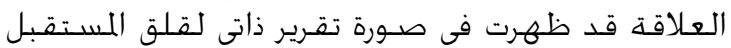
عند تذكر الأحـداث السـلبية لدى العينة أكثر من اجترار

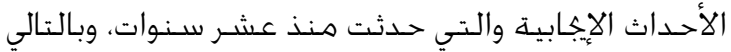

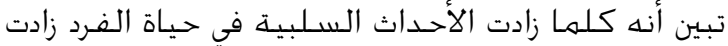
معها معدلات القلق المستقبلي. الاحداث السيات

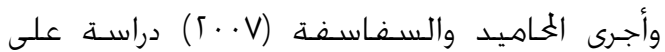

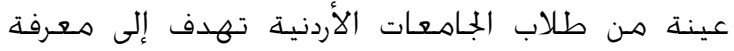
مستوى قلق المستقبل المهني وعلاقته ببعض الماته المتغيرات.

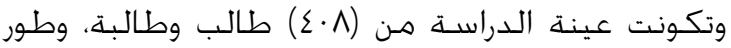

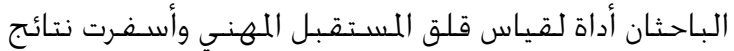

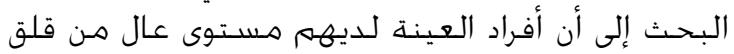

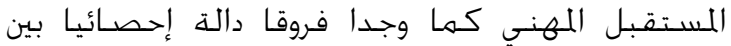

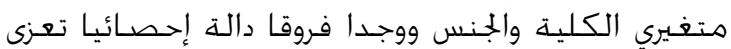

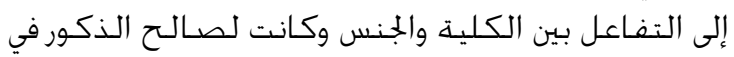
الكليات العلمية.

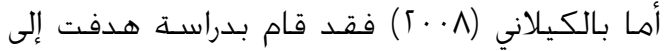

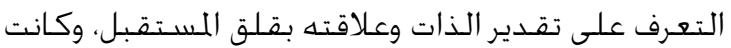

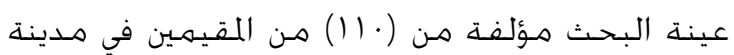

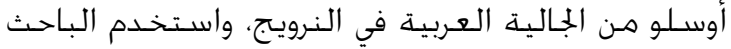

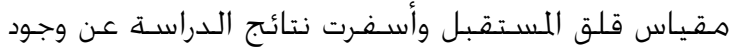

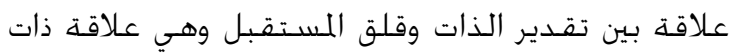

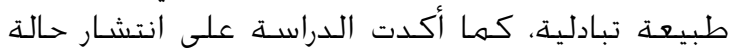

$$
\text { قلق المستقبل لدى أفراد العينة. }
$$

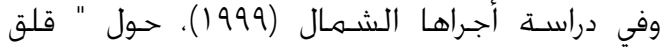

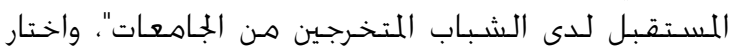

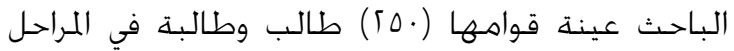

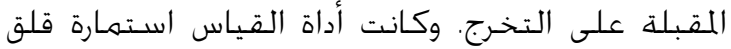

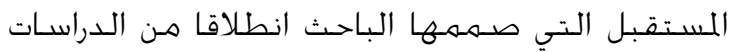

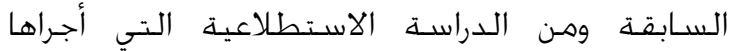

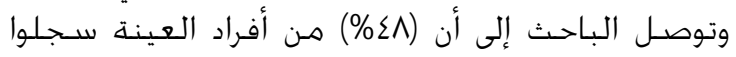

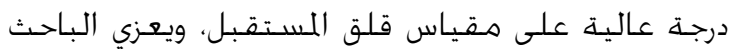

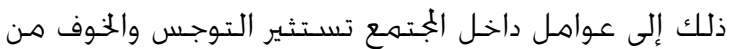

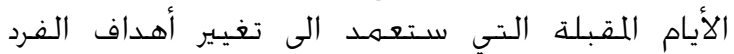

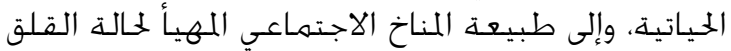

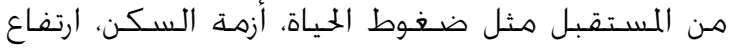

أسباب قلق المستقبل:

يظهر قلق المستقبل نتيجة مجموعة هن العوامل

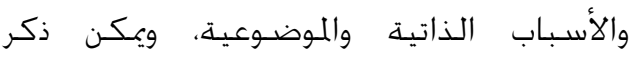
بعضها فيما يلي: - الابية

1 - غمـوض المستقبل وعدم وضـوحهـ يؤدي إلى ارتفاع نسبة القلق. ؟ - التوقعات السلبية للأحداث ولا هو آت.

$$
\text { " - نقص مهارات إدراك المستقبل. }
$$

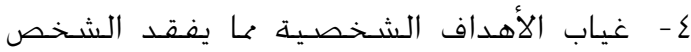
معنى الحياة ويسبب له اضطراب القلق.

0 - نقص التخطيط للمستقبل والعجز عن التحكم التمع

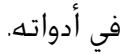

1 - ضعف مهارات التنفيذ واختاذ القرار، وهذه السـلبية جُعل الفرد ختـت سيطرة التردد والشكـك. V - Vياب أو غموض مشـروع الحياة لدى الشخص.

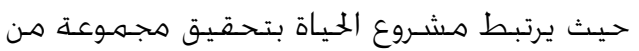

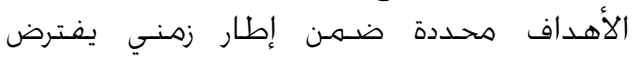
الإمكانية والقدرة على تصور الوضع الحساف الحالي

والمستقبلي. (Ibara, 2006 ; Guichard,1997) ^- الخبرات السيئة الناجَّة عن طبيعة التنشئة الاجتماعية التي مر بها الشخص.

9 - الأفكار الخاطئة واللاعقلانية لدى الفرد والتي

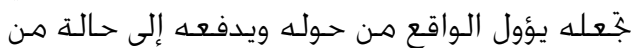

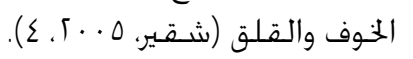

ويحدد مولين (M oline, 1990) مجموعة من الأسباب المثيرة لقلق المستقبل والمتمثلة فيك

• عدم قدرة الفرد على التكيف مع مشاكل الحياة.

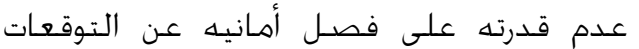
المبنية على الواقع. • المشكلات الأسرية داخل البيت والعجز عن إيجاد

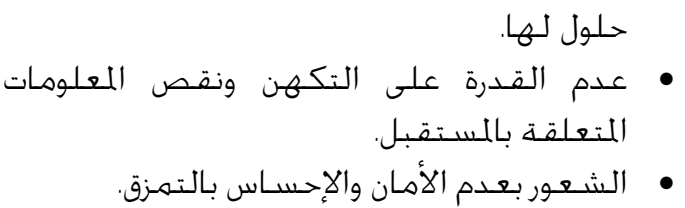

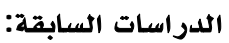

أجرى بن طاهر (· (· ؟) دراسـة هدفت إلى التعرف

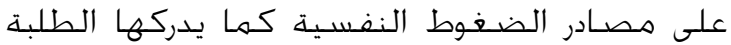

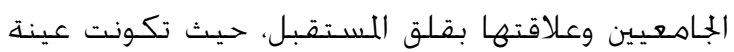

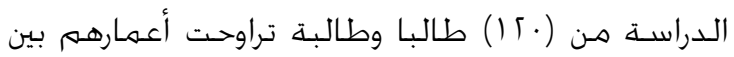

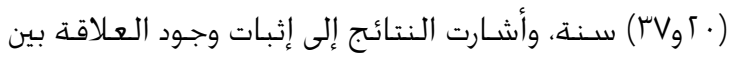

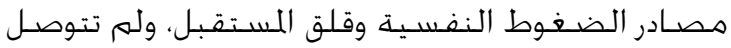


با - توفر الدراسـة معلومات للمختصين في الإرشاد

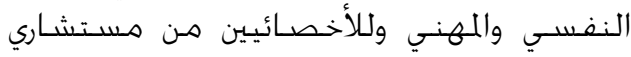

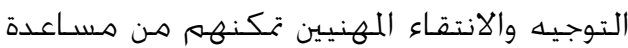

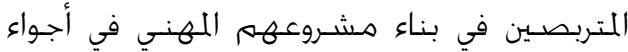
خالية من القلق أو يقل فيهاء مقروعاه القلق.

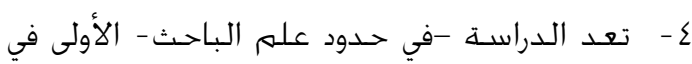

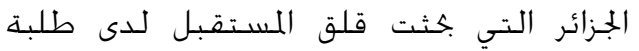

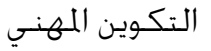

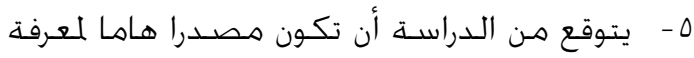
واقع الشباب وجمع معطياته في ظل التحراس التحولات

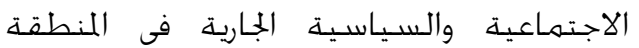
العربية.

هدف الدر اسة:"

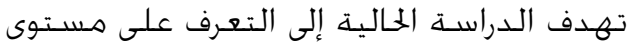

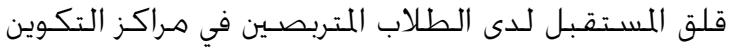

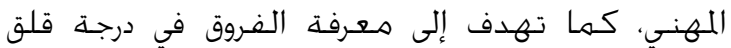
المستقبل بالنسبة لكل من الجنس والتخصص الفرف المهني.

مشكلة الدر اسة وأسئلتها:

يشغل قلق المستقبل حيزا كبيرا من المشكـلات

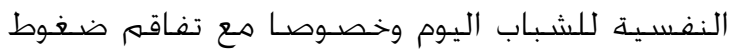

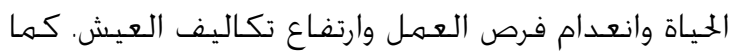

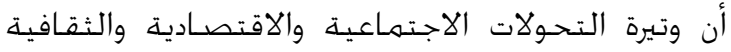

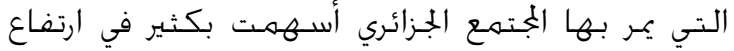

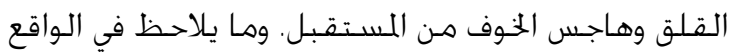

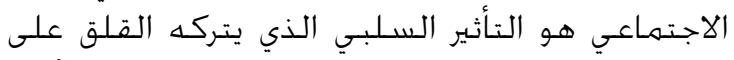

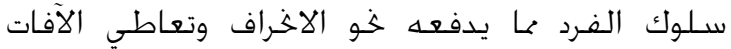

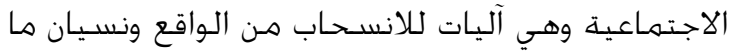

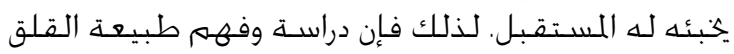

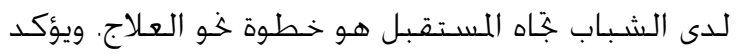

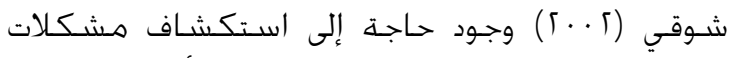

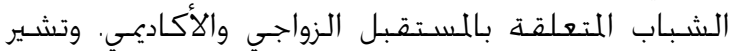

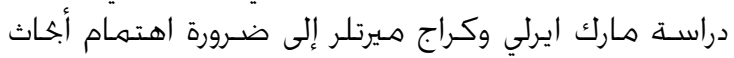

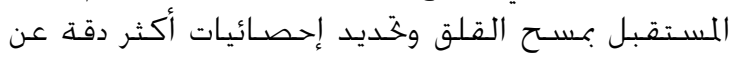

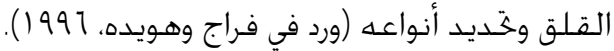

وتعتبر شريحة الشباب والمراهقين المتربصين في في المئي

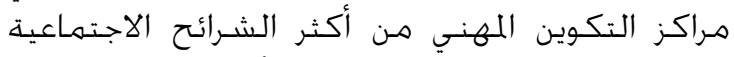

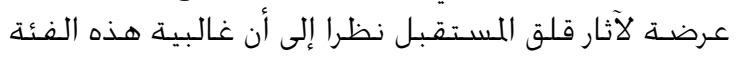

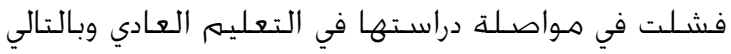

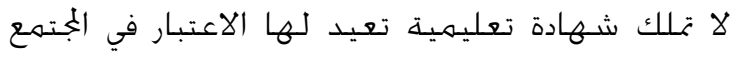

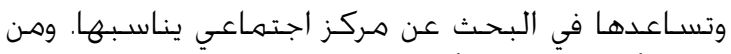

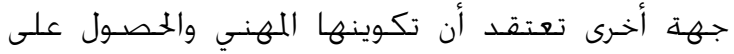

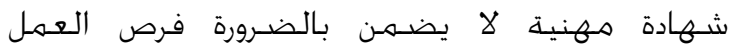

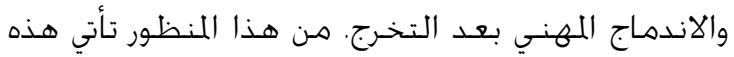

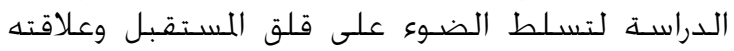

الأسعار، غياب العدالة التوزيعية وقلة فرص العمل

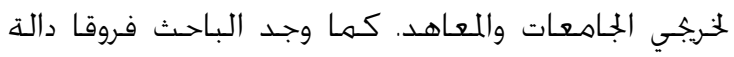

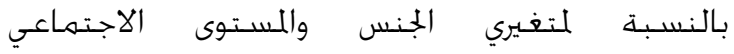
والاقتصادي.

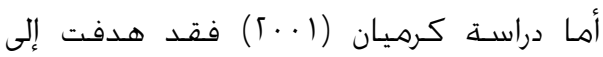

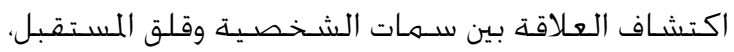

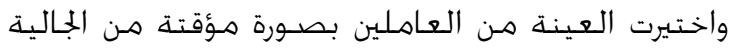

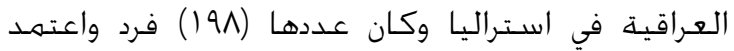

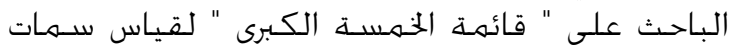

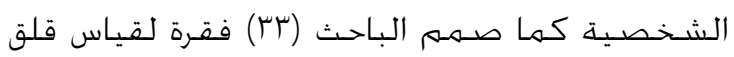

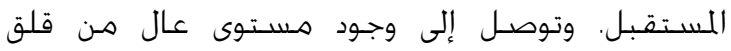

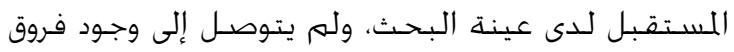

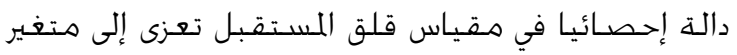

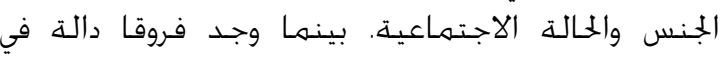

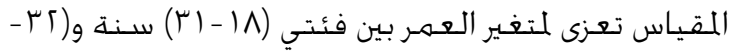
ع ع) سـنة وكانت لصالح الأخيرة.

من خلال هذا العرض يمكن أن نسجل الملاحظات الXتيـة:

- أكدت الدراسـات السـابقة على انتشار قلق لقالق المستقبل لدى الشباب بمستوى عال.

- معظم الدراسـات استخـدمت المنهج الوصفي. في حين اتبعت دراسـات أخرى المنهج التجريبي.

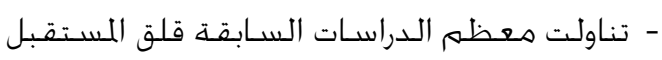

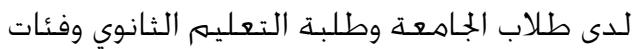

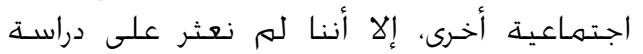

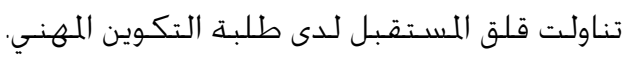

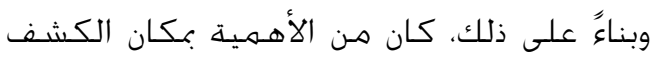

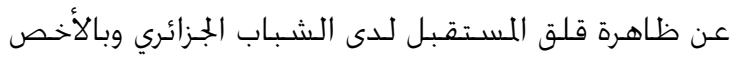

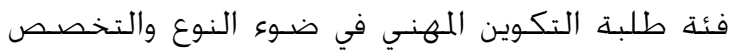

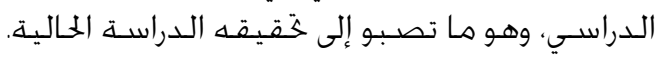

\section{أهمية الدراسة: - أل}

تأتي أهمية الدراسة من الأهمية البالغة

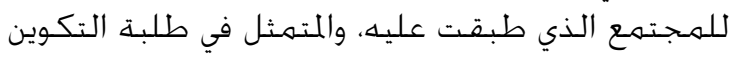

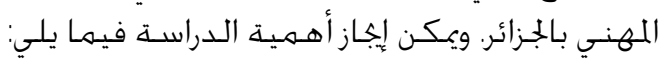

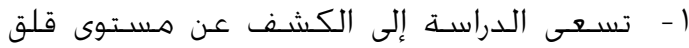

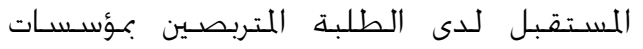

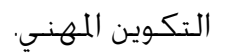

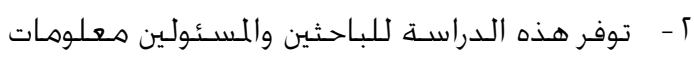

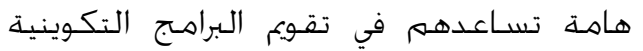

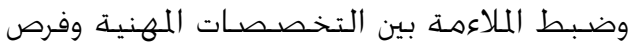

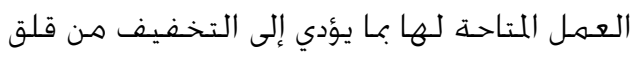
المستقبل 
ويعرّفهـ ريكمان (Rickman) بأنه "إحسـاس مـؤلم

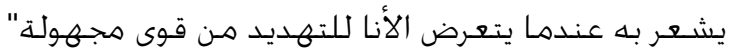

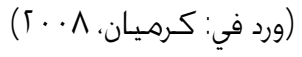

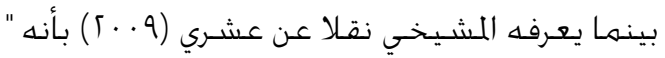

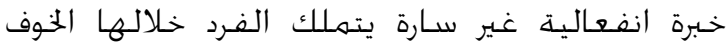

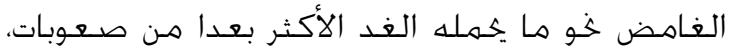

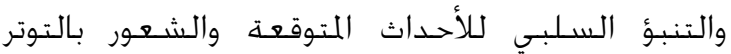

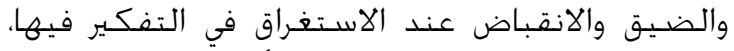

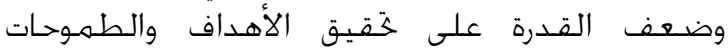

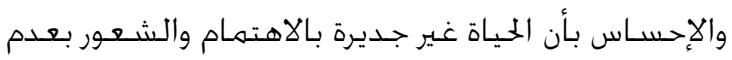

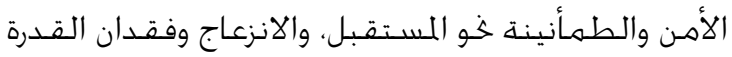

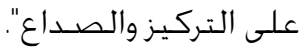

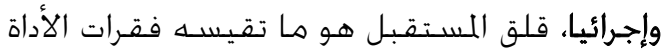

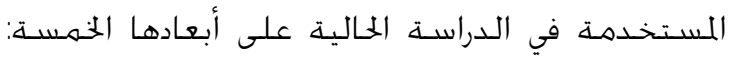

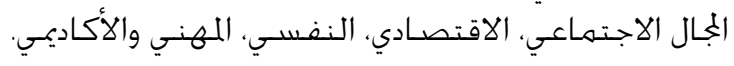

\section{الطريقة والإجراءات}

\section{منهج الدراسة:}

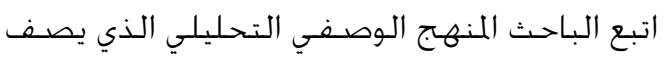

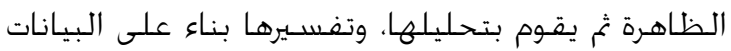
التي تم جسمعها.

\section{مجتمع الدراسة:}

تكـون مجتمع الدراسـة مـن الطلبة المتربصـين

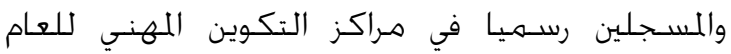

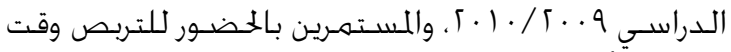

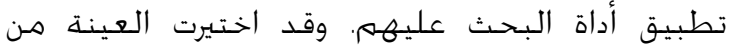

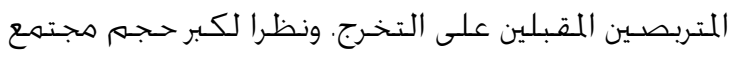

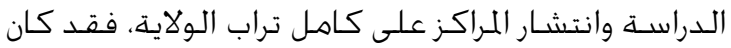

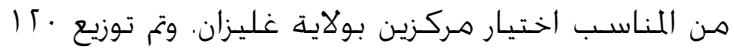

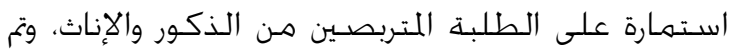
اختيارهم على أسـاس التخـص المص اللفتوح بالمركز. وقد

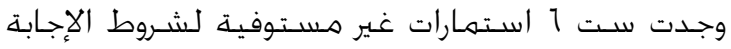

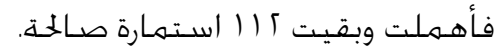

\section{جدول ا}

\begin{tabular}{|c|c|c|c|}
\hline 17 & .7 & 1. & محاسبة \\
\hline$\varepsilon$. & rq & .1 & سكرتارية \\
\hline 1. & & 1. & كهرباء \\
\hline$\leq 7$ & 1. & r & إعلام آلي \\
\hline 114 & $v \wedge$ & $r \varepsilon$ & المجموع \\
\hline
\end{tabular}

توزيع عينة الدراسة حسب الجنس والتخصص الدراسي الجنس إن الدموع
ببعض المتغيرات (الجنس والتخصـص الدراسي) وهـن ثم

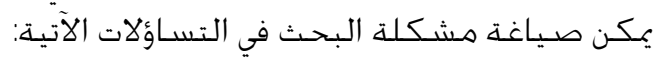

- ما مسـتوى قلق المستقبل لدى شـريكة الشـباب

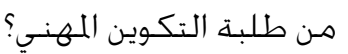

- هل هناك فروق بين الجنسيـن في قلق المستقبل وأبعاده الفـرعية؟ فن فئ بـ

- هل توجـد فروق في قلق المستقبل تعود إلى نوع

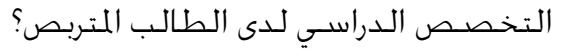

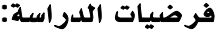

هـن خـلال هذه التسـاؤلات يمكـن صـياغـة الفرضـيات الآتية:

ا - ترتفع درجـة قلق المسـتقبل لدى الطلبة المتربصـين

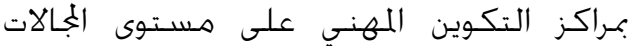
الخمسـة للأداة.

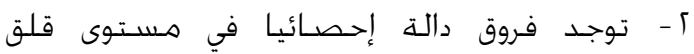

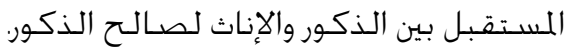

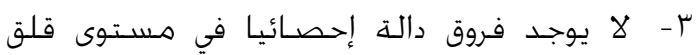

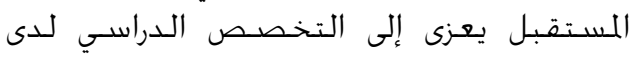
المتربـ.

حدود الدراسة:

يتحـدد البحـث الحالي بمجهموعة مـن الحـدود كما يأني: الحدود الموضـوعية: تقـتصـر الدراسـة على معـرفة

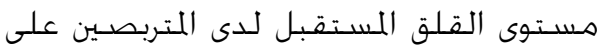

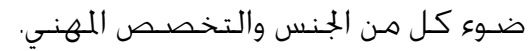

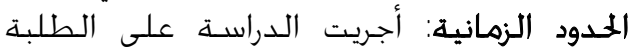

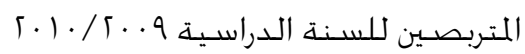

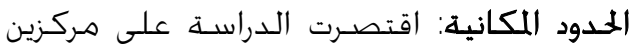
للتكوين المهني بولاية غليزان (الجزائر).

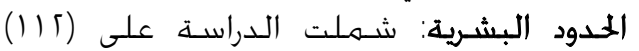
متربصـا ومتربصـة هـن المركزين.

\section{التعريف الإجر ائي للمصطلحات:}

قلق المستقبل: يعرفه زالسـكي (Zaleski, 1996)

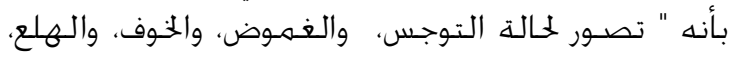

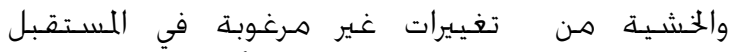

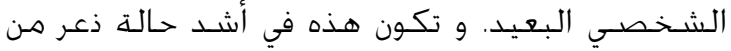

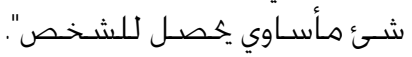
ويعرفه عادل شكري (999 () على أنه " خـبرة

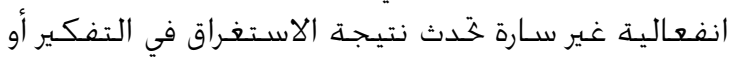

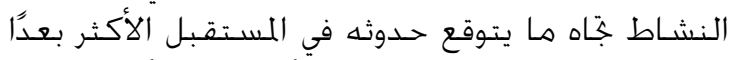

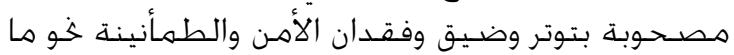

سيـحـدث في المسـتقبل." 
ثم قام الباحث بحسـاب معامل الارتباط بين كل عبارة

$$
\text { والبعد الذي تنتهـي إليه. }
$$

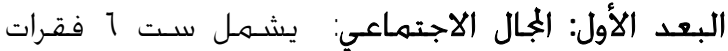

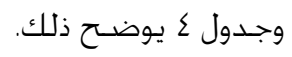

جدول ؛

معامل الارتباط بين كل عبارة من عبارات المجال الاجتماعي والمجموع الكلي للبعد

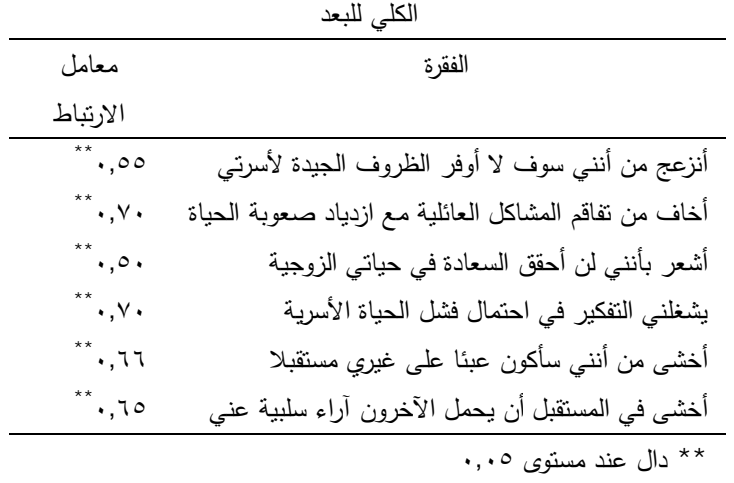

البعد الثاني: الجال الاقتصـادي يتضـــن خـمس ه فقـرات.

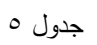

معامل الارتباط بين كل عبارة من عبارات المجال الاقتصادي والمجموع

\begin{tabular}{|c|c|}
\hline معامل الارتباط & 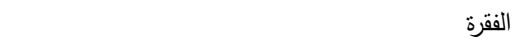 \\
\hline ** & مستقبلي من أن تكون تغيرات اقتصاد البلد قد تهدد \\
\hline $\begin{array}{l}{ }^{* *} \cdot, 0 \leq \\
{ }^{* *} \cdot, 74\end{array}$ & فيقلقني ارتفاع في تكلفادة أسعار المواد في الأسواق بنسبة عالية السكن الإيجار أونسبة الفائدة) \\
\hline${ }^{* *} \cdot, \vee \vee 4$ & تشغلني مشكلة غلاء المعيشة باستمرار . \\
\hline${ }^{* *} \cdot, 01$ & المتزايدة. \\
\hline
\end{tabular}
الكلي للبعد

البعد الثالث: الجال النفسـي ويشــمل على خـمس هـ فقرات.

$$
\text { جدول } 1
$$

\begin{tabular}{|c|c|}
\hline معامل & 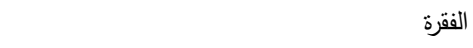 \\
\hline \multicolumn{2}{|l|}{ الارتباط } \\
\hline${ }^{* *} \cdot$, , ८० & ززاودني فكرة موت شخص عزيز علي \\
\hline${ }^{* *} \cdot$, ov & أشعر بالطمأنينة والهدوء بالنسبة لحياتي المستقبلية \\
\hline${ }^{* *} \cdot, \leq 0$ & يخيفني فقدان الأمن النفسي \\
\hline${ }^{* *} \cdot, \times 1$ & برهبني التفكير بأنني قد أواجه أزمات وصعوبات \\
\hline${ }^{*} \cdot, \varepsilon$ & أخاف من موت شخص قريب \\
\hline
\end{tabular}

معامل الارتباط بين كل عبارة من عبارات المجال النفسي والمجموع الكلي للبعد
أداة الدراسة: - الد

يعـد الاسـتبيان الأداة الأسـاسـيـة في الدراسـة، والذي

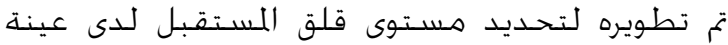

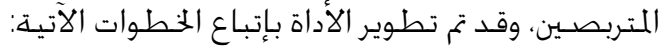

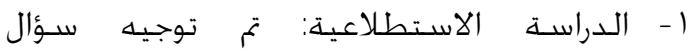

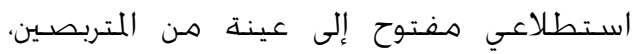

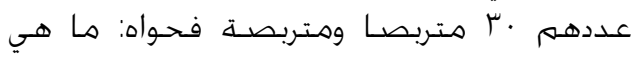

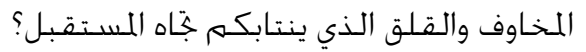

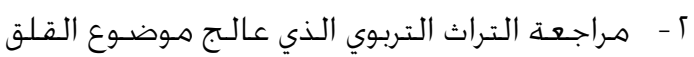

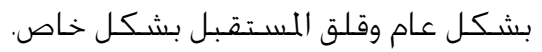

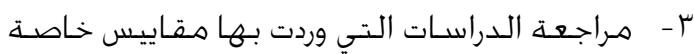

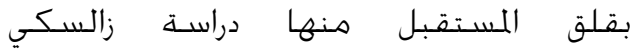

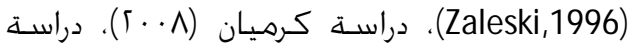

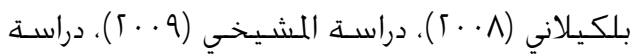

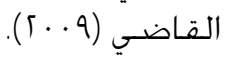
وقد استفاد الباحث هـن الاطلاع على الدراسـات

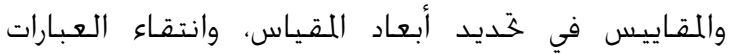

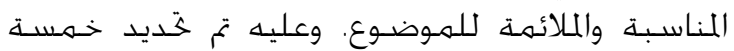

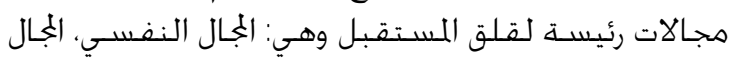

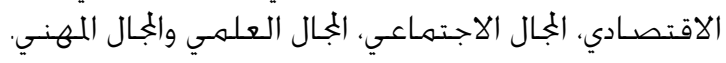

\begin{tabular}{|c|c|}
\hline الفقرات & الأبعاد \\
\hline T- 0- $\leqslant-r-Y-1$ & المجال الاجتماعي \\
\hline $11-1 \cdot-9-1-v$ & المجال الاقتصادي \\
\hline $1 V-17-10-1 \leqslant-1 Y-1 Y$ & المجال النفسي \\
\hline$r \leq-Y r-Y r-Y 1-Y--19-11$ & المجال المهني \\
\hline$r \cdot-r q-Y A-r V-r r_{-} r_{O}$ & المجال الأكاديمي \\
\hline
\end{tabular}

$$
\text { جدول r المبنوب }
$$

توزيع فقرات أداة قلق المستقبل على الأبعاد الخمسة

\section{الخصائص السيكومترية للأداة:}

طبقت الأداة في صـورتها الأوليـة على عينة استطلاعية

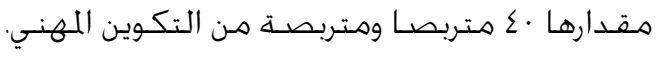

$$
\text { أ - حسـاب الصسدق: }
$$

\begin{tabular}{|c|c|}
\hline معامل الارتباط & 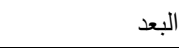 \\
\hline${ }^{* *} \cdot$, OV & المجال الاجتماعي \\
\hline${ }^{* *} \cdot$, rᄉ & المجال الاقتصادي \\
\hline${ }^{* *} \cdot, V Y$ & المجال النفسي \\
\hline${ }^{* *} \cdot, \wedge \Gamma$ & المجال المهني \\
\hline${ }^{* *} \cdot, 09$ & المجال الأكاديمي \\
\hline
\end{tabular}

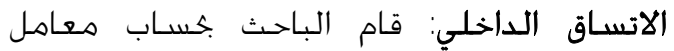

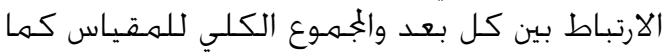

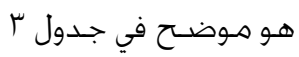

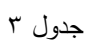


1 - المتوسـ الحسبابي والاخراف العياري. ا - معامل ألفا كرونباخ (Cronbach's alpha) لحساب

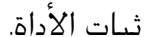

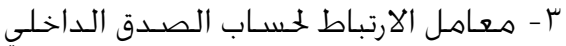
ع - اختبار ت (t-test) لدراسـة الفروق بين الذابـ الذكور والإناث.

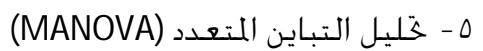

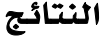

سـيتهم عرض نتائج الدراسـة وفقا لتسـلسـل فرضياتها كما يلي:

أولا: نتائج الفرضية الأولى: تنص الفرضية الأولى في

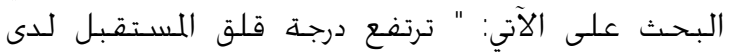

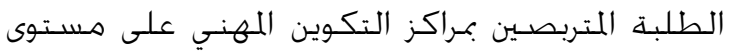

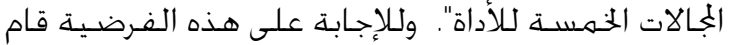

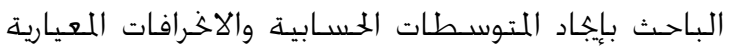

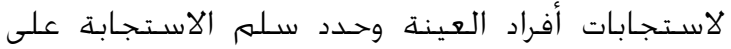

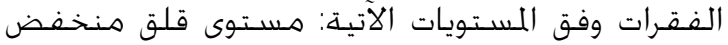

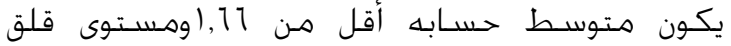

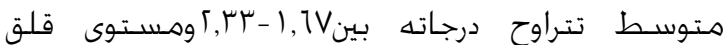

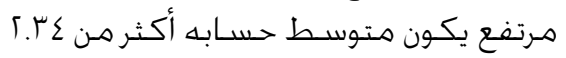

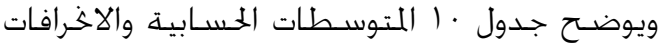

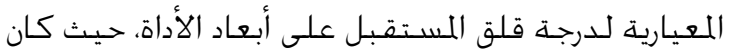

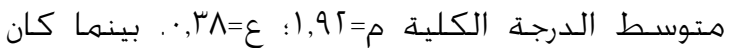

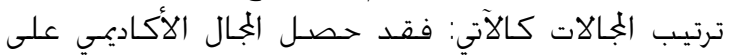

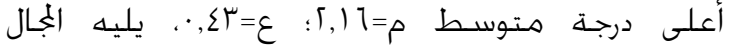

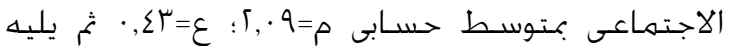

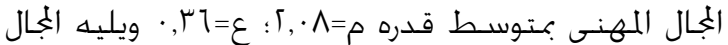

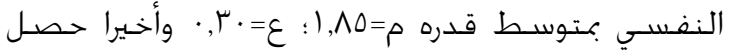

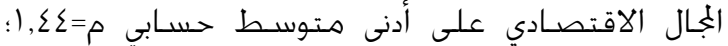

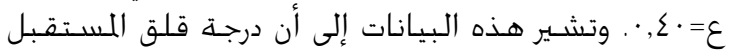

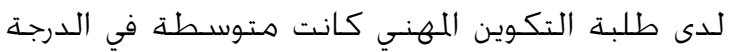

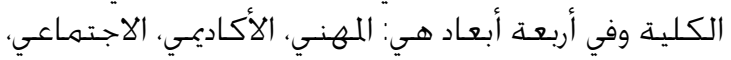

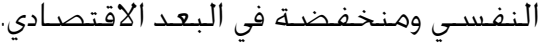

جدول 1.

المتوسط الحسابي والانحراف المعياري والرتب لدرجة قلق المستقبل في أبعاد الأداة

\begin{tabular}{|c|c|c|c|c|}
\hline مستوى القلق & لانحراف & الحستوسط & العينة & الأبعاد \\
\hline منوسط & $\cdot$, ऍ & $1,9 r$ & $11 r$ & الأداة الكلية \\
\hline منوسط & •, $\leqslant \Gamma$ & r.1T & 115 & المجال الأكاديمي \\
\hline متوسط & •, & $r, .9$ & $11 r$ & المجال الاجتماعي \\
\hline منوسط & דז, & $r, \cdot \Lambda$ & 115 & المجال المهني \\
\hline متوسط & $\cdot, r$. & 1,10 & 115 & المجال النفسي \\
\hline منخفض & $\cdot, \varepsilon$. & $1, \varepsilon \varepsilon$ & 114 & المجال الاقتصادي \\
\hline
\end{tabular}

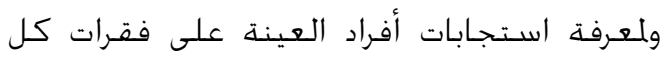

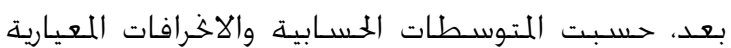

البعد الرابع: الجلال المهنـي ويتضـهـن سـبع V فقـرات.

$$
\text { جدول v }
$$

معامل الارتباط بين كل عبارة من عبارات المجال المهني والمجموع الكلي

للبعد

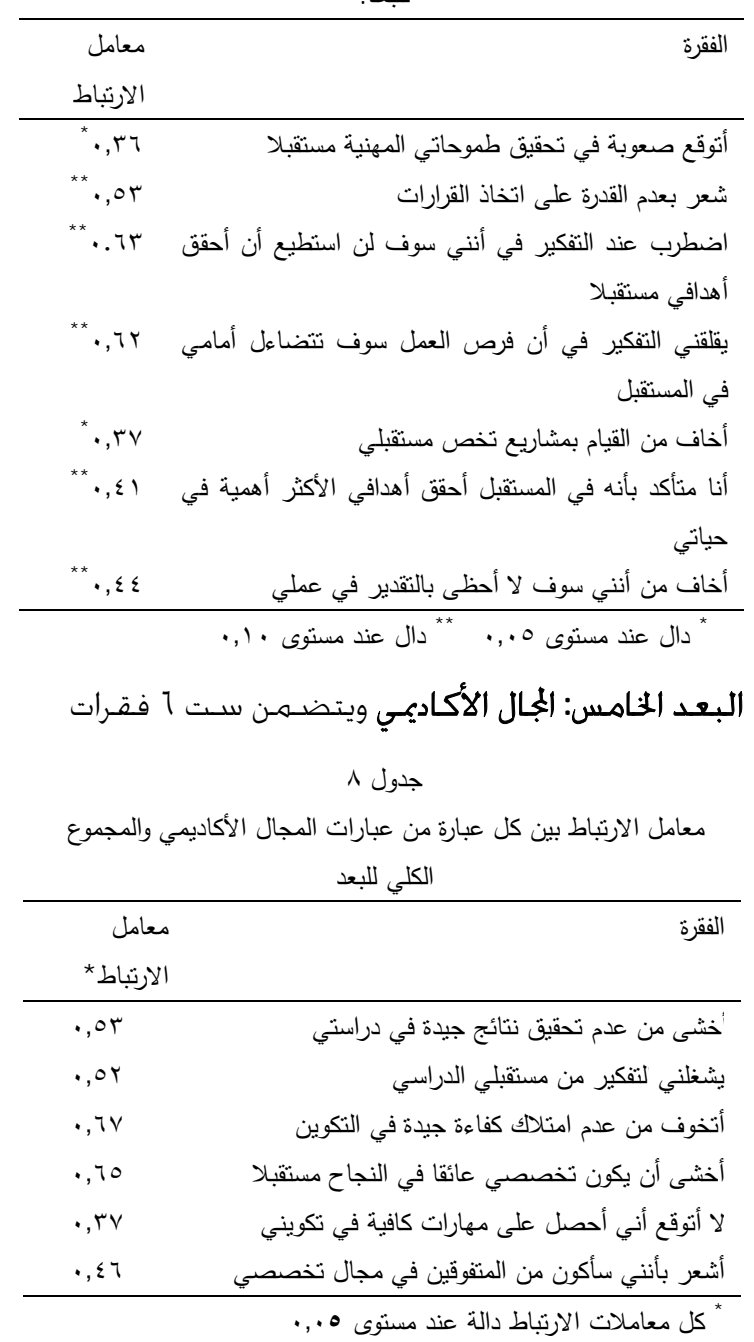

ب - حساب الثبات: تم حسـاب ثبات الأداة بطريقة معامل

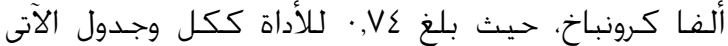
يوضح معامل ألفـا لكل بُعد.

جدول 9

معامل الفا كرونباخ لكل مجال وللأداة ككل

\begin{tabular}{|c|c|}
\hline معامل ألفا كرونباخ & الفقرة \\
\hline , vo & المجال الاجنماعي \\
\hline$\cdot, Y \leqslant$ & المجال الاقتصادي \\
\hline$\cdot, 7 \wedge$ & المجال النفسي \\
\hline$\cdot, 7 \wedge$ & المجال المهني \\
\hline$\cdot, \mathrm{VT}$ & المجال الأكاديمي \\
\hline$\cdot, V \varepsilon$ & الأداة ككل \\
\hline
\end{tabular}

استخـدم الباحث في معالجة بيانات الدراسـة

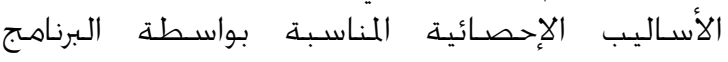
الإحصائي (SPSS)، حيث تم حسـاب: 
جدول

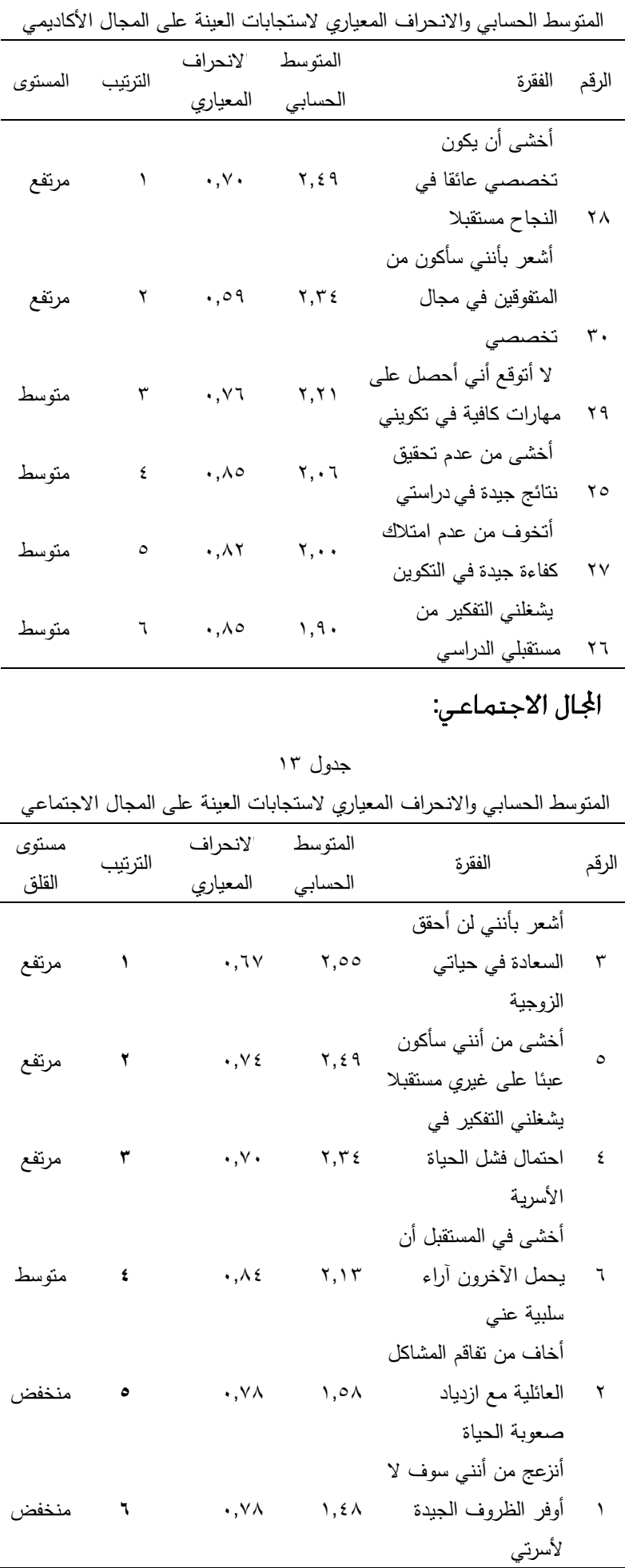

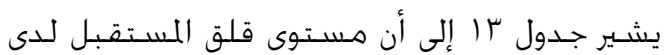

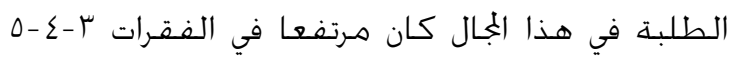

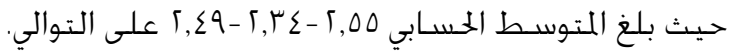

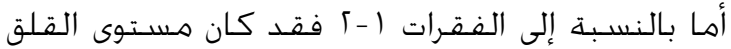

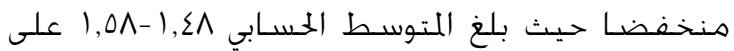

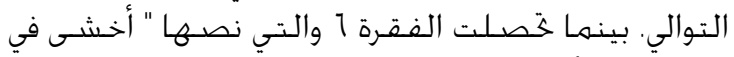

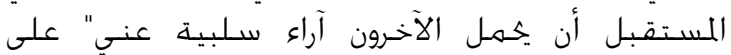

للفقرات كما هو موضح في الجداول ذات الأرقام || I| I $.101<1 \%$

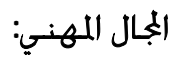

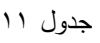

\begin{tabular}{|c|c|c|c|c|c|}
\hline المستوى & الترتيب & ل المعباري & الحتوسط & الفقرة & الرقم \\
\hline منوسط & 1 & $\cdot, V T$ & $r, r q$ & أخاف من أنني سوف لا لالتقدير في عملي & $r \varepsilon$ \\
\hline متوسط & $r$ & $\cdot, V T$ & $r, r q$ & تخص مستقبلي من القيام بمشاريع & r \\
\hline متوسط & $r$ & $\cdot, \gamma \cdot$ & $r, r_{1}$ & أشعاذ القعارم القدرة على & 19 \\
\hline متوسط & $\varepsilon$ & $\cdot, V T$ & 1,10 & طموحاني المهنية مستقبة في تحقيق & 11 \\
\hline متوسط & 0 & $\cdot, \wedge$. & l,Ar & 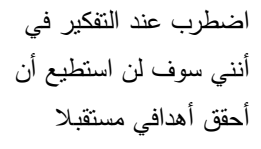 & $r$. \\
\hline متوسط & 7 & $\cdot, \lambda)$ & $1, \times 9$ & فتقرص العمل سوف التفكير في أن & $r_{1}$ \\
\hline منخفض & v & $\cdot, 7 \wedge$ & ו, & أنا منتأكد بأنه في ألمين & $r r$ \\
\hline
\end{tabular}

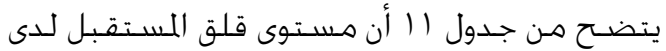

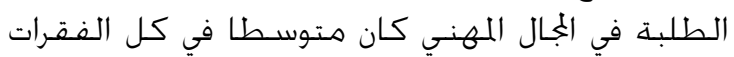

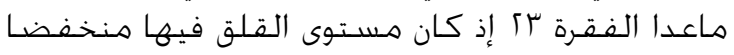

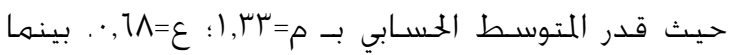

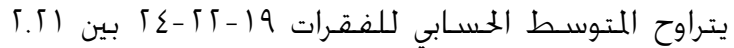

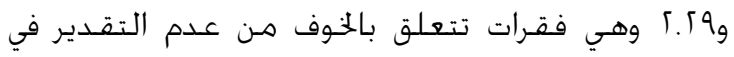

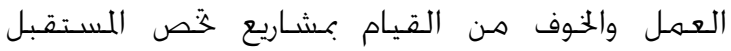

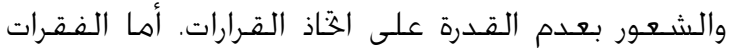

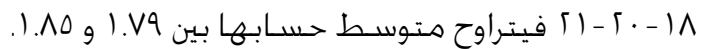

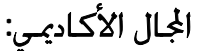

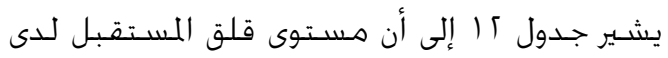

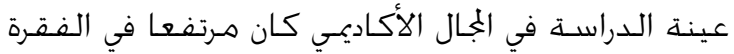

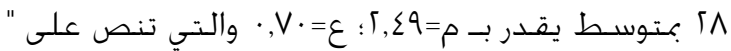

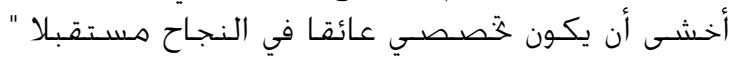

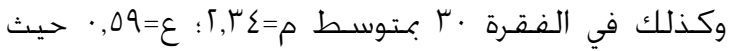

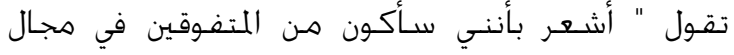

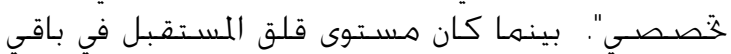

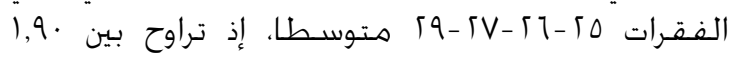
و وI, 
منخفض حسب المعيار الذي تم اعتهاده عند تفسير

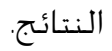

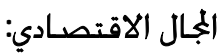

يظهر هن جدول 10 أن جهيع الفقـرات تراوح

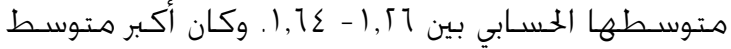

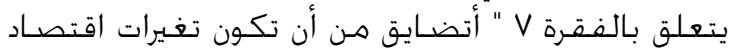

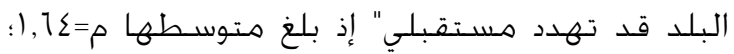

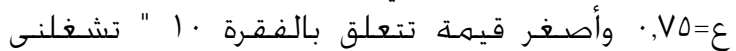

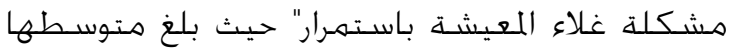

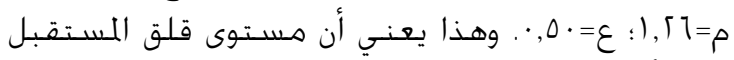

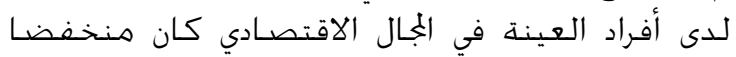
حسب المعيار الذي تم اعتماده عند تفسير الذير النتائج.

ثانيا: نتائج الفرضـية الثانية: للإجابة عن الفـرضـية

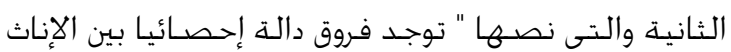

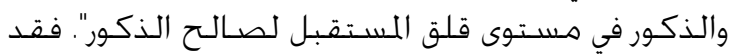

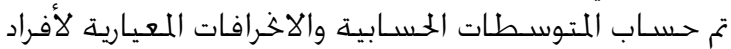

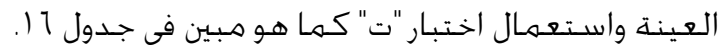
يتضح هن جدول 11 وجـود فروق ذات دلالة

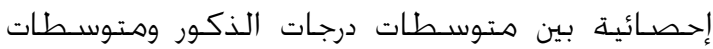

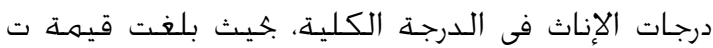

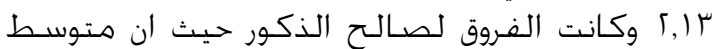

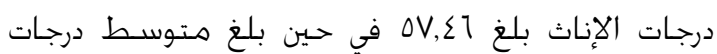

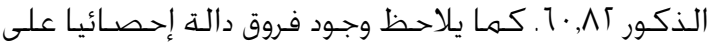

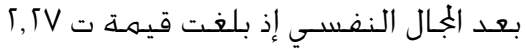

متوسـط حسـابي قدره ץ. Г وهو مسـتوى متوسـط هـن القـلق حسـب اللعيار الذي تم اعتماده عند تفـسـير النتائج.

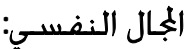

\begin{tabular}{|c|c|c|c|c|c|}
\hline ي النفسي & على المجا & يات العينة = & جاري لاستج عا & نط الحسابي والانحراف المع & \\
\hline مستوى & التزتيب & الانحراف & الحتوسط & الفقرة & الرقم \\
\hline متوسط & 1 & $\cdot, \wedge 1$ & $r, 19$ & 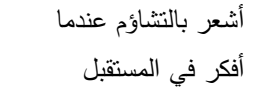 & IV \\
\hline متوسط & $r$ & $\cdot, \wedge$. & 1,99 & النفيفي فقدان الأمن & $1 \varepsilon$ \\
\hline متوسط & $r$ & $\cdot, \mathrm{V}$. & $1, \vee 9$ & بالنسبة لحياتي المستقبلية & $1 r$ \\
\hline متوسط & $\varepsilon$ & $\cdot, \wedge)$ & $1, \vee 9$ & 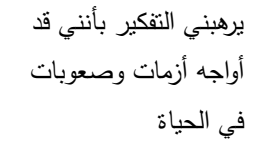 & 10 \\
\hline متوسط & 0 & $\cdot, 10$ & I,VV & عزيز علي فكرة موت شخص & Ir \\
\hline منخفض & 1 & $\cdot, \vee \vee q$ & $1,7$. & قريب من موت شخص & 17 \\
\hline
\end{tabular}

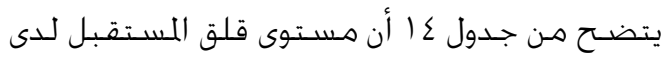

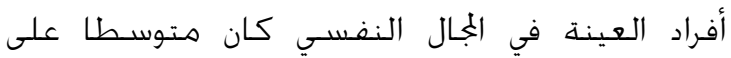

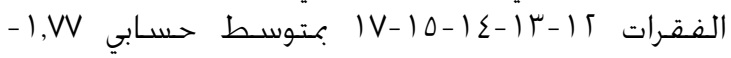
1,19 - 1,V9 - 1,99 - 1,V9

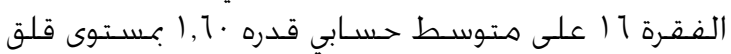

جلول 10

المتوسط الحسابي والانحراف المعياري لاستجابات العينة على المجال الاقصادي

\begin{tabular}{|c|c|c|c|c|c|}
\hline مستوى & 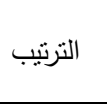 & الانحراف المعياري & الحستوسط الحسبي & 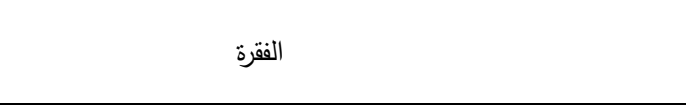 & 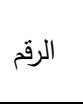 \\
\hline 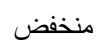 & 1 & $\cdot, v_{0}$ & $1,7 \varepsilon$ & أتضايق من أن تكون تغيرات اقتصاد البلد قد تهدد مستقبلي & $\checkmark$ \\
\hline منخفض & r & $\cdot, T \leqslant$ & 1,01 & بشغلني كثرة منطلبات الحياة والتزاماتها المادية المتزايدة. & 11 \\
\hline منخفض & r & $\cdot, \uparrow$ & $1, \varepsilon 1$ & يقلقني ارتفاع في تكلفة السكن (الإيجار أو نسبة الفائدة) في المستقبل & 9 \\
\hline 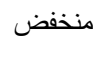 & $\varepsilon$ & $\cdot, 70$ & $1, \varepsilon$. & أتوقع زيادة أسعار المواد في الأسواق بنسبة عالية & $\wedge$ \\
\hline 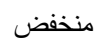 & 0 & $\cdot, 0$ & $1, r 7$ & تشغلني مشكلة غلاء المعيشة باستمرار . & 1. \\
\hline
\end{tabular}

جدول 17

المنوسط والانحراف المعياري لكل مجال حسب الجنس وقيمة ت ودلالتها الإحصائية

\begin{tabular}{|c|c|c|c|c|c|c|c|c|}
\hline \multirow{2}{*}{ مستوى الدلالة } & \multirow{2}{*}{ قيمة "ت" } & \multirow{2}{*}{ الحرية } & \multicolumn{2}{|c|}{ الإناث } & \multicolumn{2}{|c|}{ الذكور } & \multirow{2}{*}{ ن ن } & \\
\hline & & & $\varepsilon$ & 5 & $\varepsilon$ & s & & \\
\hline غير دالة & (1, 1, & 11. & $r, r V$ & דוז,r & $r, .0$ & $1 r, \cdot 9$ & $11 \mathrm{r}$ & المجال الاجتماعي \\
\hline غير دالة & $\cdot, T \vee-$ & 11. & $r, 19$ & 1,00 & $V, r)$ & $v, \cdot r$ & $11 r$ & المجال الاقتصادي \\
\hline دالة & $r, r V$ & 11. & r זr, & $1 \cdot, \vee \wedge$ & r, r & 11,10 & 114 & المجال النفسي \\
\hline دالة ل & $r, \cdot r$ & 11. & $r, r V$ & $1 \leq, r \wedge$ & $r, q$ r & 10, & $11 \mathrm{r}$ & المجال المهني \\
\hline غير دالة & $1,0 \leqslant$ & 11. & $r, 07$ & Ir,VY & r.07 & Ir,or & $11 \mathrm{r}$ & المجال الأكاديمي \\
\hline دالة ل & $r, i r$ & 11. & $\gamma, 09$ & $O V, \Sigma T$ & $\vee, \wedge T$ & $T \cdot, \Lambda T$ & $11 \mathrm{r}$ & الدرجة الكلية \\
\hline
\end{tabular}


جدول

نتائج تحليل التباين المتعدد لتوضيح دلالة الفروق بين المجالات الخمسة لقلق المستقبل تبعا لمتغير التخصص المهني

\begin{tabular}{|c|c|c|c|c|c|c|}
\hline مستوى الدلالة & قيمة "ف" & منوسط مربعات & المربعات & مجموع مربعات الخطأ & المربعات & المجالات \\
\hline$\cdot, 97 \leqslant$ & $\cdot, \ldots r$ & $1, \wedge 7$. & $1 \cdot, \varepsilon \ldots$ & $r \cdot T, 00 \leqslant$ & $1 \cdot, \varepsilon \ldots$ & المجال الاجتماعي \\
\hline$\cdot, V T$. & $\cdot, Y_{l}$. & 1,10 & 1,. 74 & r.o, ro. & $\Lambda, \cdot 77$ & المجال الاقتصادي \\
\hline$\cdot, \wedge \uparrow$. & $\cdot, \cdot \times q$ & $r, Y, Y$ & $11, \cdots 1$ & $r \leq 7, T \leq$. & $11, \cdots 1$ & المجال النفسي \\
\hline$\cdot, \vee \wedge$. & $\cdot, Y) \cdot$ & r,YOV & $17,00 \leqslant$ & $r 0 ., 7) 1$ & $17,00 \leqslant$ & المجال المهني \\
\hline$\cdot, 9 \cdot \varepsilon$ & $\cdot, 114$ & $r, \varepsilon r\}$ & $7, \times 1$. & 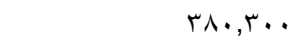 & $7, \vee 1$. & المجال الأكاديمي \\
\hline
\end{tabular}

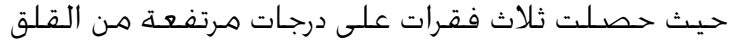

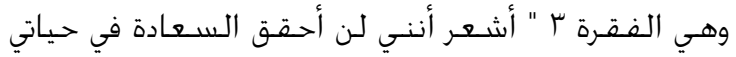

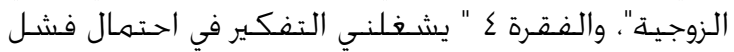

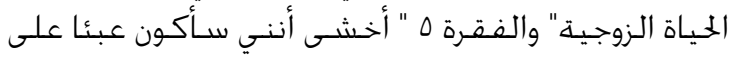

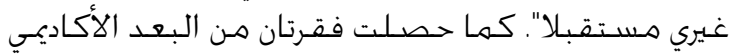

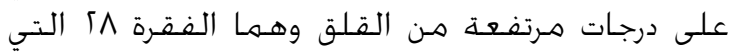

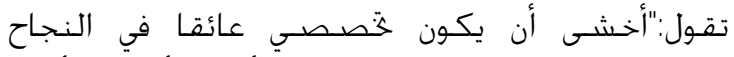

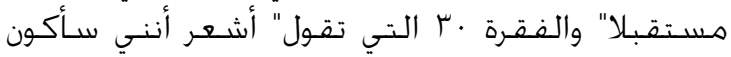
هـن المتفوقين في مجال ختصـصـي". ويمكـن أن نرجع ذلك إلى جَربة الفشـل الدراسـي التي

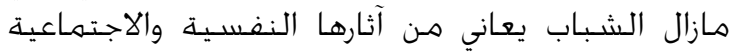

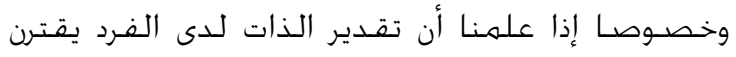

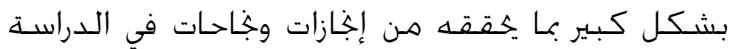

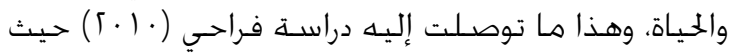

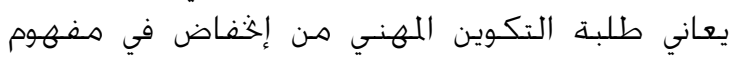

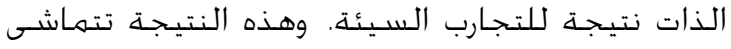

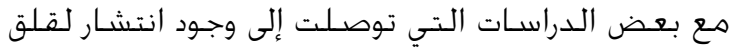

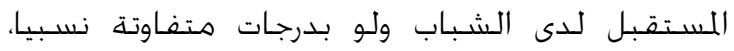

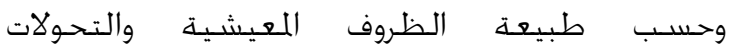

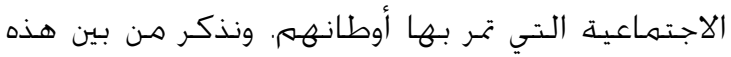

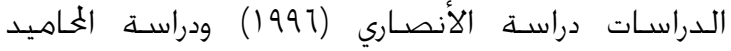

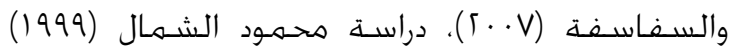

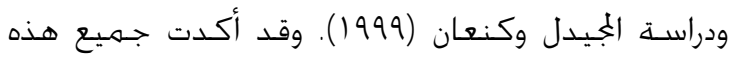

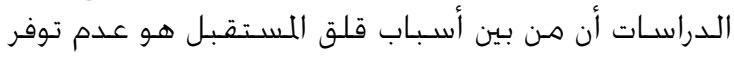

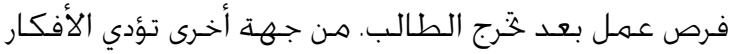

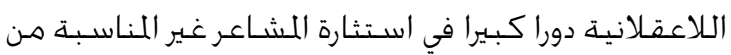

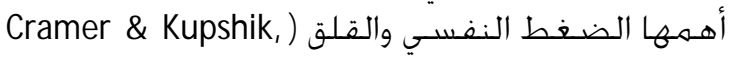

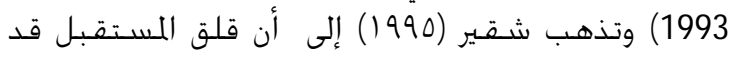

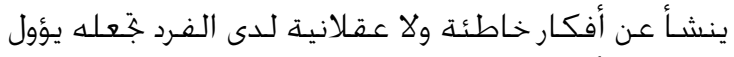

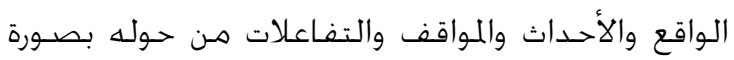

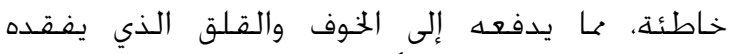

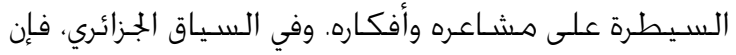

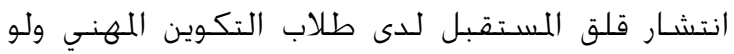

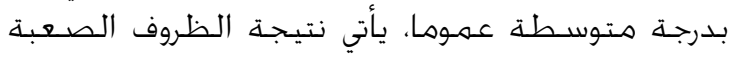

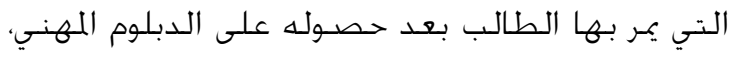

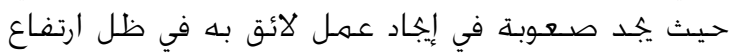

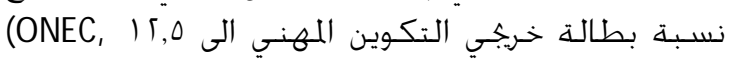

وكانت لصـالح الذكور، حيث إن متوسـط درجات الذكور

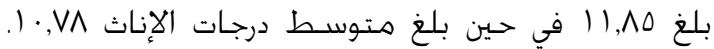

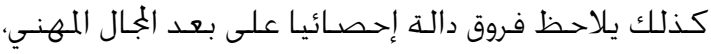

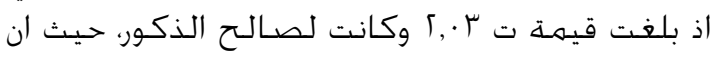

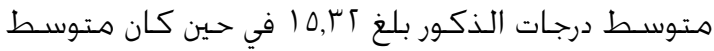

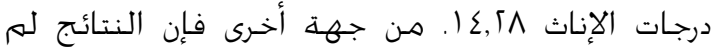

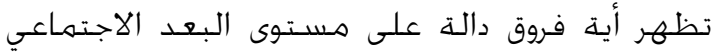
والبعـد الاقتصـادي والبعـد الأكـاديمسي.

ثالثا: نتائج الفرضية الثالثة: للإجابة على الفـرضية

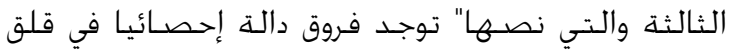

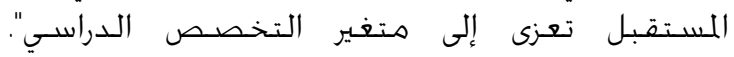

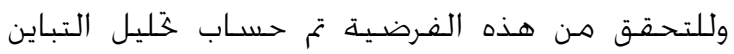

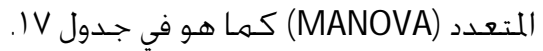

يتضح مـن خـال تطبيق ختليل التباين المتعدد عدم

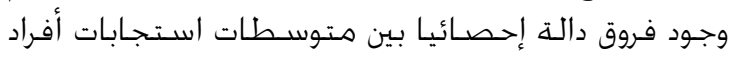

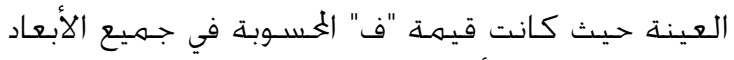

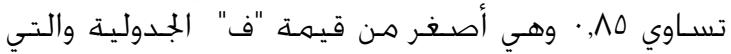

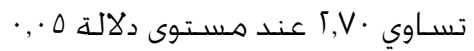

\section{مناقشة النتائج}

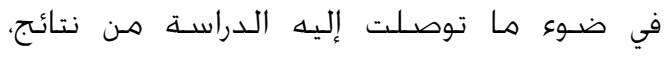

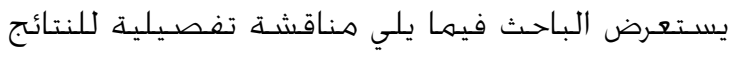

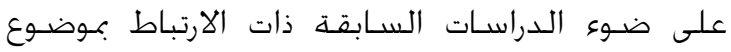

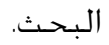

\section{مناقشـة نتائج الفرضية الأولى الخاصـة بدرجة

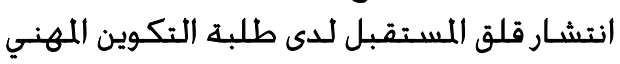

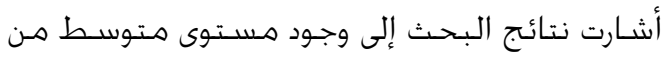

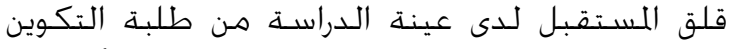

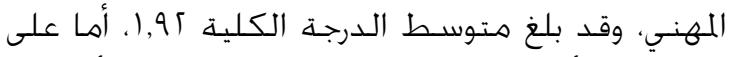

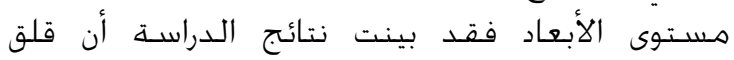

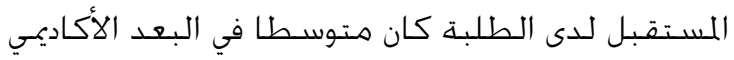

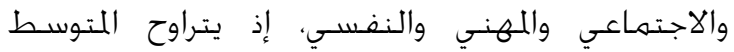

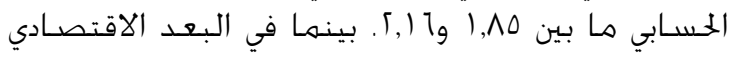

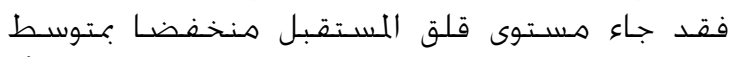

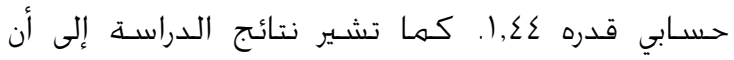

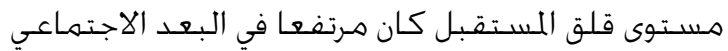


بتنشئة الإناث في ثقافة الجُتمع الجزائري ختّلف عن الجن الجناف

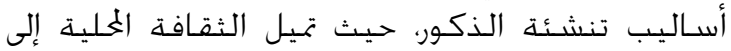

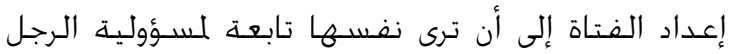

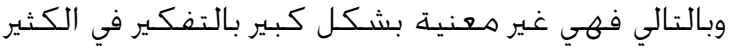

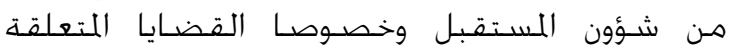
بالمهنة والعائلة. وعليه فإن الجُتمع الجزائري بطبيعته

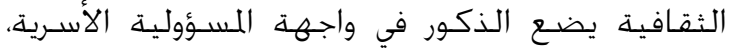

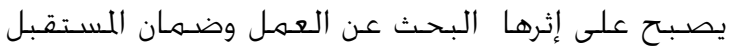

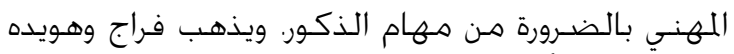

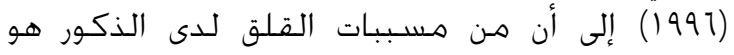

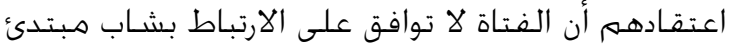
ليس لديه الإمكانيات التي يقدمها لهان الها.

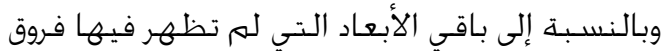

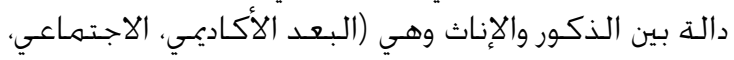

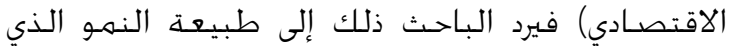

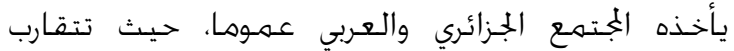

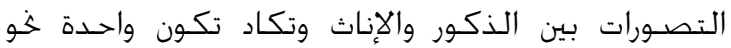
الدراسـة وبناء الأسـرة والتكفل بأعباء العائلة والسـكن والِكن

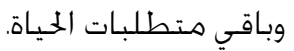

\section{مناقشـة نتائج الفرضية الثالثة والمتعلقة بدراسة}

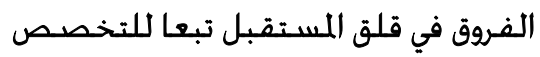

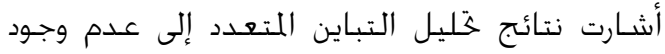

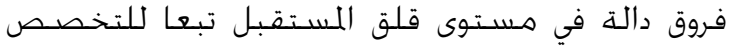

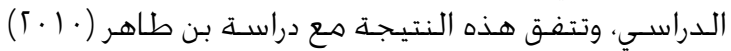

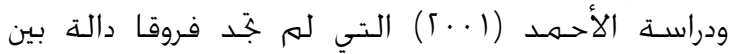

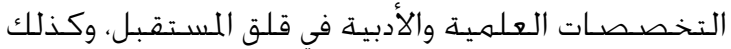

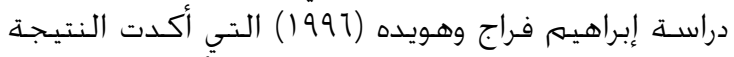

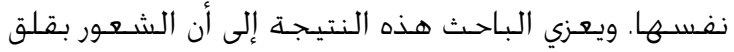

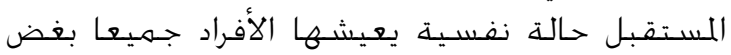

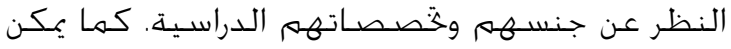

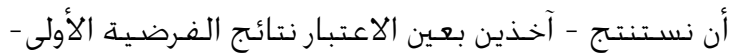

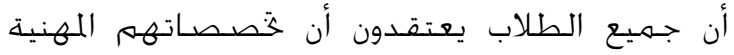

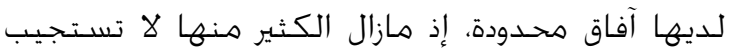

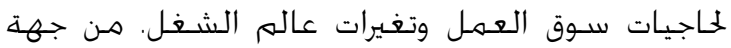

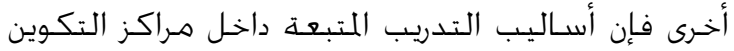

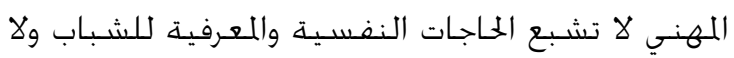
تعطي لهم الإعداد الكافي لمواجهة مشكلاتلات الحياة.

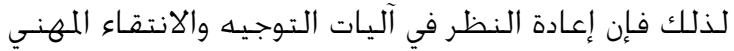

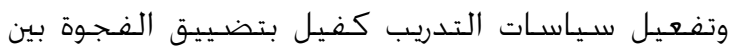

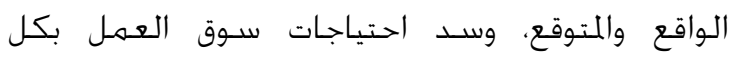
التخصصات المهنية.

وانطلاقا من كون جَربة قلق المستقبل تنبع مـن تمثلات معرفية حسببما يرى زالسكي (Z) (Zaleski)

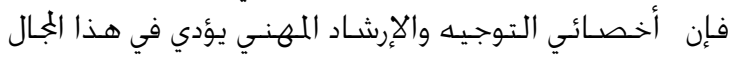

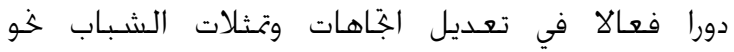
المستقبل عبر توفير المعلومة الصـحيحة عن المهن
(2010. كما يزداد التوتر والاضطراب أكثر لدى الشـباب

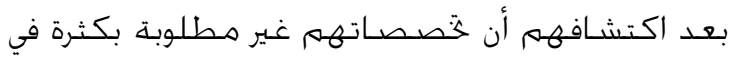

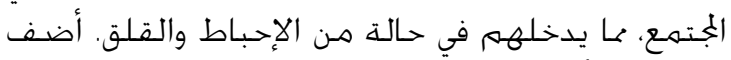

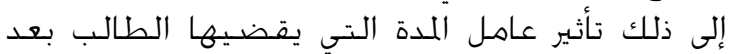

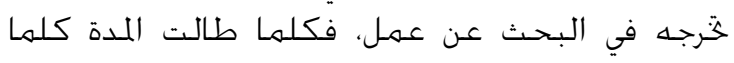

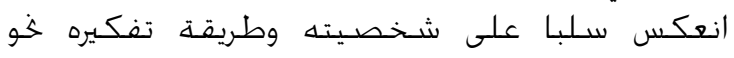

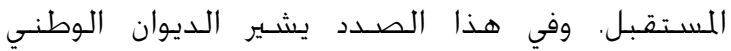

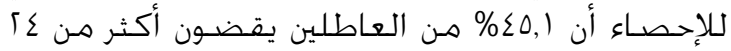

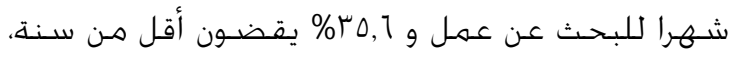

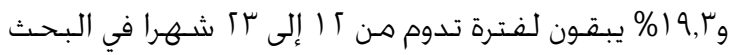
عن عمل (ONEC, 2010).

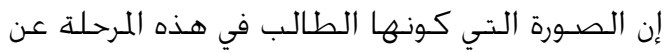

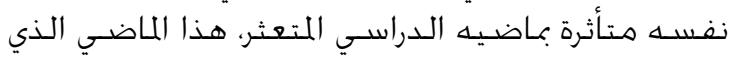

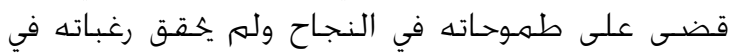

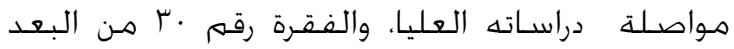

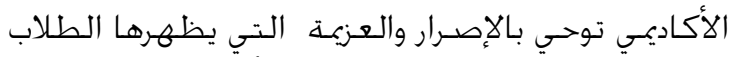

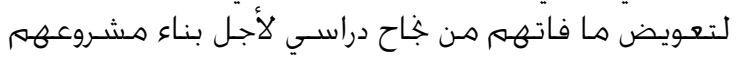

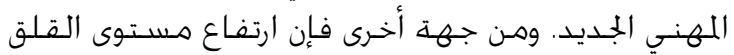

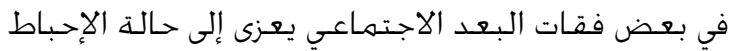

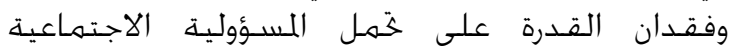

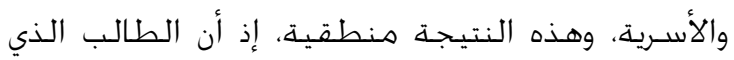

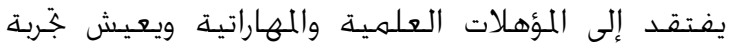
الفشـل الدراسي يشعـ بنوع من خيبة أهل في بنـاء أسـرة

ناجحة في المستقبل.

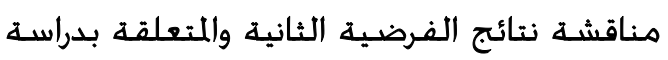
الفروق في قلق المستقبل تبعا للجنس (ذكور وإناث)

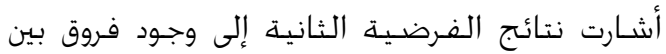

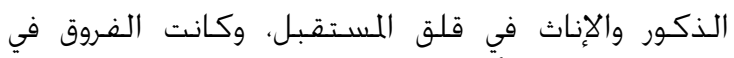

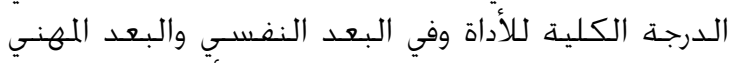

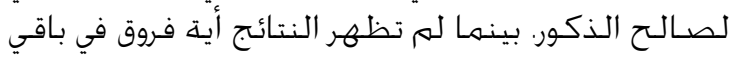

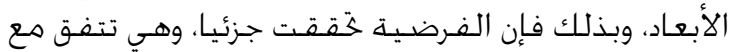

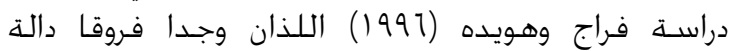

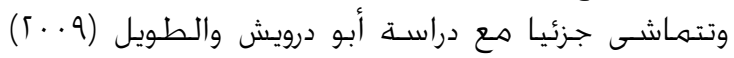

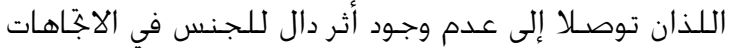

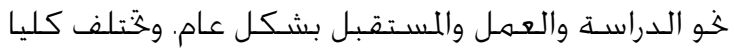

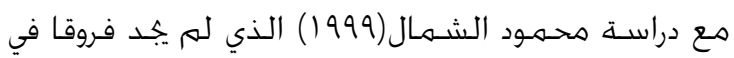
قلق المستقبل لدى الخريجين الجامعيين.

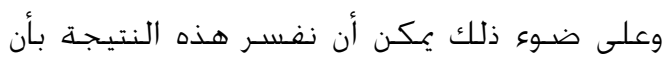

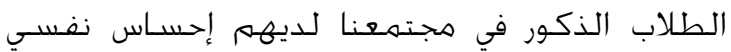

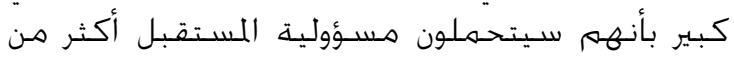

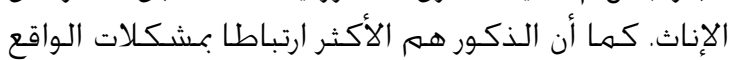

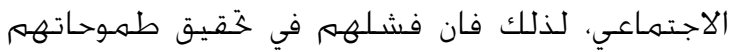

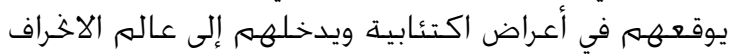

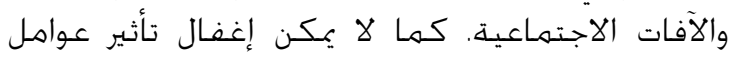
التنشئة الاجتماعية في تفسير الفروق بين الجنسئسين في الاعني

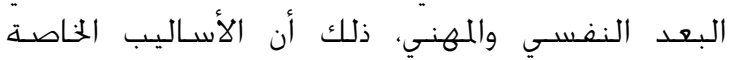


الحرب على غزة. (رسـالة ماجسـتير غير منشـورة الجامعة الإسـلامية غزئة).

الطويل، هاشـم محهمد (1 ؟). الجّاهـات الطلبة العرب في

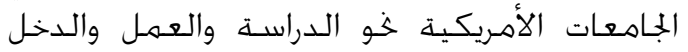

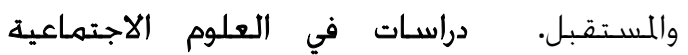

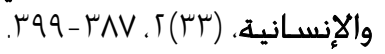

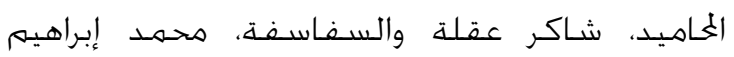

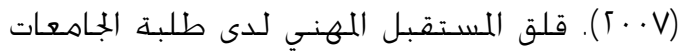

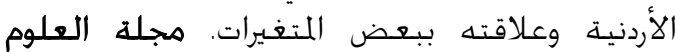

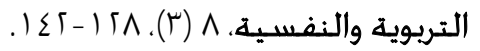

بلكيلاني، ابراهيم بن محمد (^ . ). تقدير الذات وعلاقته بقلق المستقبل لدى الجالية العربية المقيمة بمدينة

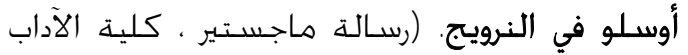

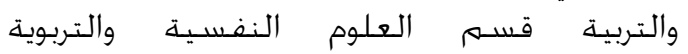

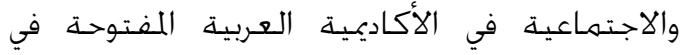

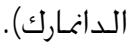

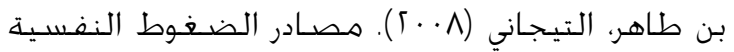

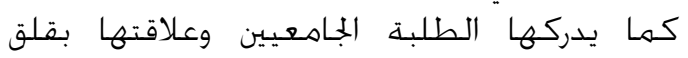
المستقبل على عينة هن طلبة جامعة الاغواط.

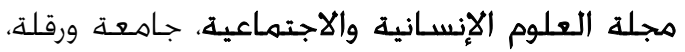

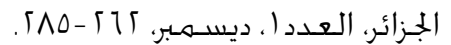

تونسـي، عديلة حسـن طاهر (؟ .؟). القلق والاكتئاب

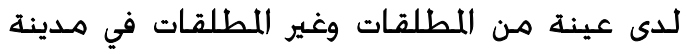

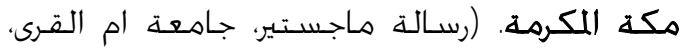

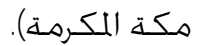

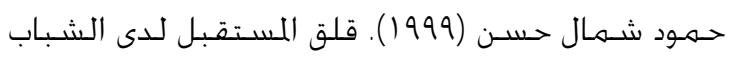

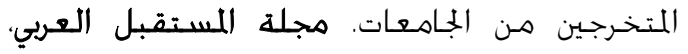

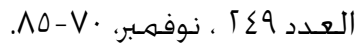

زقاوة، أحسمد (· ( ·)). دور نظم التنمية البشـرية في الحد

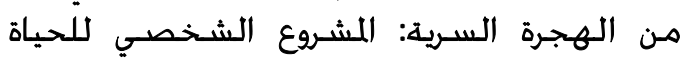

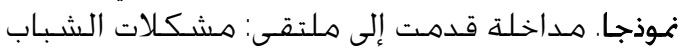

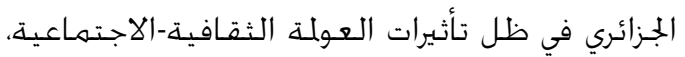

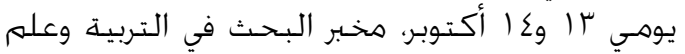
النفس، جامعة وهـران، الجزائر.

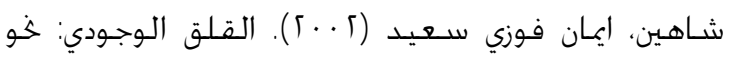

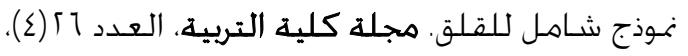
.V「- 9

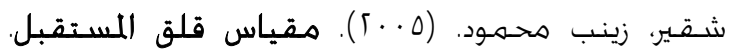
الاجنلو مصـرية، القـاهـرة.

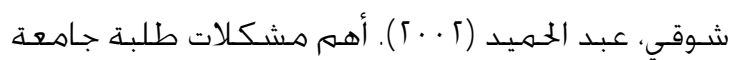

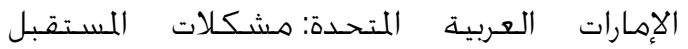

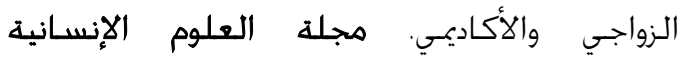

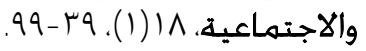

المتوافـرة في السـوق والمنافذ المفتوحـة أمـام التخـصـصـات.

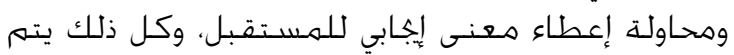

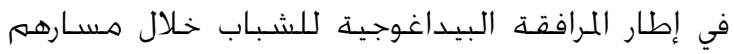

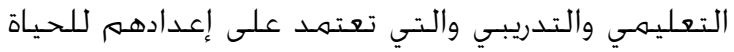

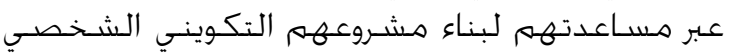
القـائم على أسـس واقعـيـة وعقـلانيـة خحددها الأبعـاد الآتية:

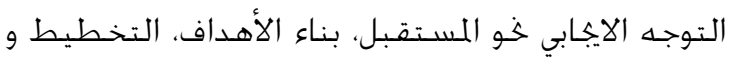

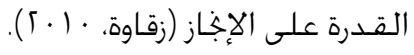

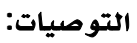

تنـطلق توصـيات هـذه الدراســة مـن واقع النتائج

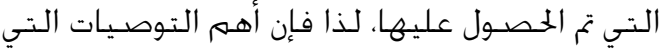
يمكن طرحها تتمثل فيما يلي:

ا - اختيار أفضل وأجع الأسـاليب للتوجيه والانتقـاء المهنيين.

ז - ربط وختديث التخصصات المهنية لتسـتجيب

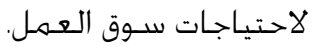

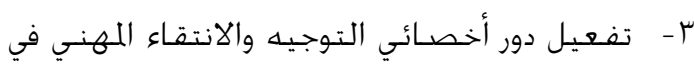

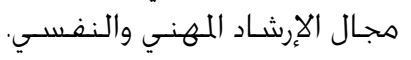

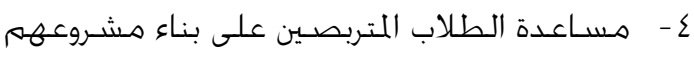
المهني.

0 - إدماج براهـ الإرشاد النفسي داخل مؤسـسـات التكـوين المهني.

1 - إجراء المزيد هـن الدراسـات حول قلق المسـتقبل

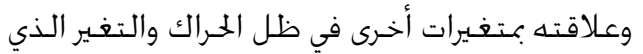
تشهده السـاحة العربية. V - إجراء المزيد هـن الدراسـات حول قلق المســقبل لدى

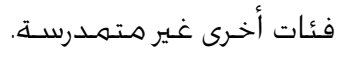

\section{المراجع}

المراجع العربية:

أبو درويش، منسى و الطويل، هاشـم (9 ؟). اجّاهات طلبة

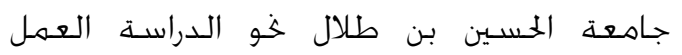

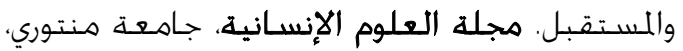

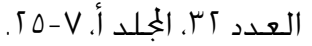

أبو عيطة، سهام درويش ( ( . ؟). مبادئ الإرشاد النفسي

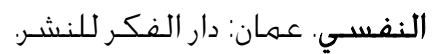

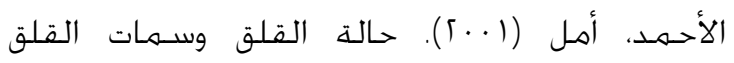

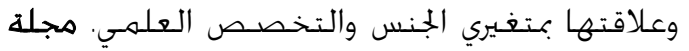

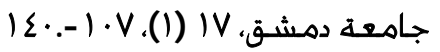

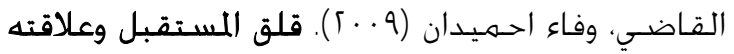

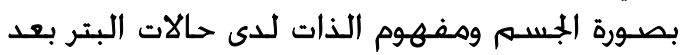


كفافي، عـلاء الدين (9901). الصحة النفسية. قطر: هجر

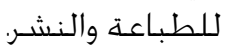

كنعان، احسمد علي والجيديدل، عبد اللّه (1999). الشـباب

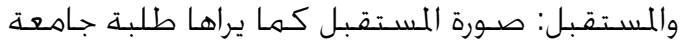

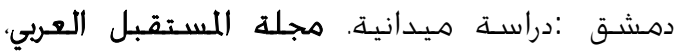

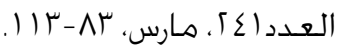

موسىى، نظمي عودة (949 ()). دراسات في علم النفس المرضي. مصـر: دار عالم الكتب. نمئ.

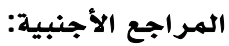

Cramer, D. \& Kupshik, G. (1993) Effect of rational and irrational statements on intensity and 'inappropriateness' of emotional distress and irrational beliefs in psychotherapy patients. British Journal of Clinical Psychology, 32, (3), 319-325.

Guichard, J. (1997). Les projets personnels des adolescents : projets du présent ou projets d'avenir? In Collectif, L' orientation face aux mutations du travail (pp. 81-88). Paris: Editions Syros.

Ibarra Arana, C. E. (2006). L'élaboration du projet de vie chez les jeunes adultes, (thèse de Doctorat a I'Université de Fribourg, en Suisse), Retrieved on May, 2008 from http:/ / ethesis.unifr.ch/ theses/ downloads .php?file=1 barraC.pdf.

ONEC. (2010). Emploi ET Chômage au 4ème Trimestre, Retrieved from: http:/ / www.onec.dz, on May 20, 2011

Moline, R. (1990). Future anxiety: clinical issues of children in the latter phases of foster care child and adolescent. Social W ork Journal, 7(6), 501-512.

Passing. D. (2003). Future time span as a cognitive skill in futures studies. Futures, Research Q uarterly. 19 (4), 27-47.

Super, D. E. (1980). A life-span, life-space approach to career development Journal of V ocational Behavior, 16, 282-298.

Zaleski. Z. (1993). Attitudes face à I'avenir, espoir et anxiété. Revue québécoise de Psychologie. 14(1), 85 - 111.

Zaleski, Z. (1996). Future Anxiety: concept, measurement, and preliminary research. Person Individidual Differences,21 (2), 165 174

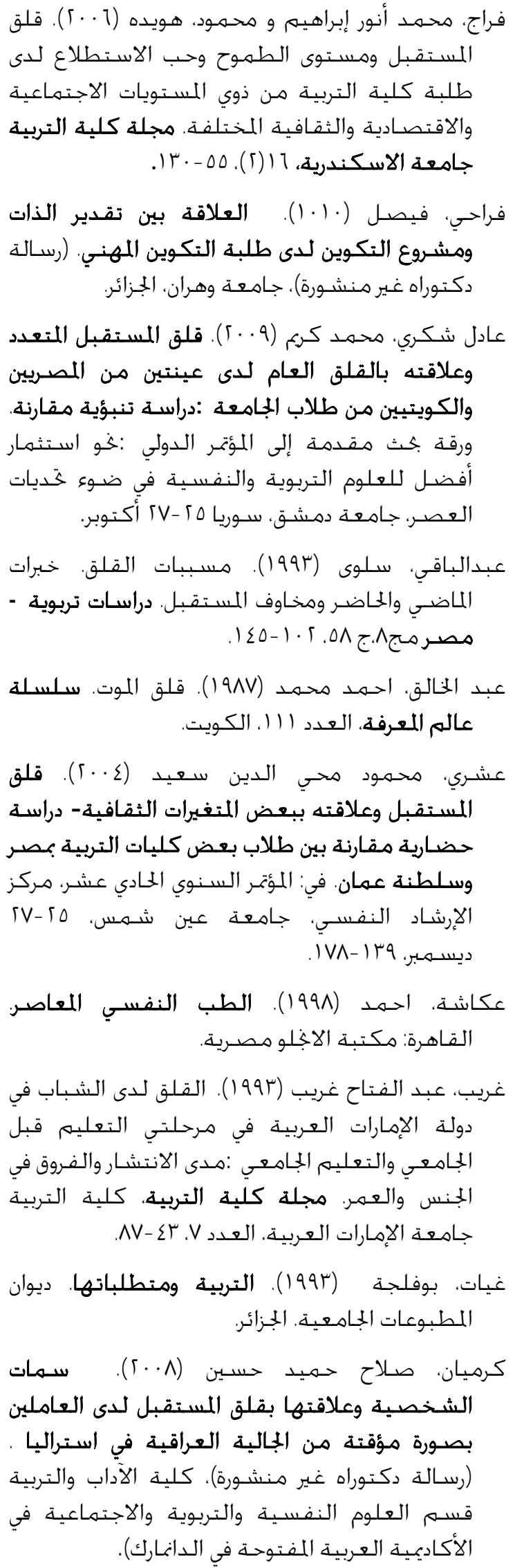

